\title{
Recent advances in smart biotechnology: Hydrogels and nanocarriers for tailored bioactive molecules depot
}

Milcovich, Gesmi; Lettieri, Stefania; Antunes, Filipe E.; Medronho, Bruno; Fonseca, Ana C.; Coelho, Jorge F.J.; Marizza, Paolo; Perrone, Francesca; Farra, Rossella; Dapas, Barbara

Total number of authors:

13

Published in:

Advances in Colloid and Interface Science

Link to article, DOI:

10.1016/j.cis.2017.05.009

Publication date:

2017

Document Version

Peer reviewed version

Link back to DTU Orbit

Citation $(A P A)$ :

Milcovich, G., Lettieri, S., Antunes, F. E., Medronho, B., Fonseca, A. C., Coelho, J. F. J., Marizza, P., Perrone, F., Farra, R., Dapas, B., Grassi, G., Grassi, M., \& Giordani, S. (2017). Recent advances in smart biotechnology: Hydrogels and nanocarriers for tailored bioactive molecules depot. Advances in Colloid and Interface Science, 249, 163-180. https://doi.org/10.1016/j.cis.2017.05.009

\section{General rights}

Copyright and moral rights for the publications made accessible in the public portal are retained by the authors and/or other copyright owners and it is a condition of accessing publications that users recognise and abide by the legal requirements associated with these rights.

- Users may download and print one copy of any publication from the public portal for the purpose of private study or research.

- You may not further distribute the material or use it for any profit-making activity or commercial gain

- You may freely distribute the URL identifying the publication in the public portal 
Historical Perspective

\title{
Recent advances in smart biotechnology: Hydrogels and nanocarriers for tailored bioactive molecules depot
}

\author{
Gesmi Milcovich $^{\mathrm{a}}$, Stefania Lettieri ${ }^{\mathrm{a}}$, Filipe E. Antunes ${ }^{\mathrm{b}}$, Bruno Medronho ${ }^{\mathrm{c}}$, Ana C. Fonseca ${ }^{\mathrm{d}}$, \\ Jorge F.J. Coelho ${ }^{\mathrm{d}}$, Paolo Marizza ${ }^{\mathrm{e}}$, Francesca Perrone ${ }^{\mathrm{f}}$, Rossella Farra ${ }^{\mathrm{f}}$, Barbara Dapas ${ }^{\mathrm{f}}$, \\ Gabriele Grassi ${ }^{\mathrm{f}}$, Mario Grassi ${ }^{\mathrm{g}}$, Silvia Giordani ${ }^{\mathrm{a}, \mathrm{h}, *}$ \\ ${ }^{a}$ Nano Carbon Materials Research Lab, Istituto Italiano di Tecnologia (IIT), Via Morego 30, 16163 Genova, Italy \\ ${ }^{b}$ Coimbra Chemistry Centre, Dept. of Chemistry, University of Coimbra, Rua Larga, Coimbra, Portugal \\ ${ }^{\mathrm{c}}$ Faculty of Sciences and Technology (MEDITBIO), University of Algarve, Campus de Gambelas, Ed. 8, 8005-139 Faro, Portugal \\ d CEMMPRE, Department of Chemical Engineering, University of Coimbra, Polo II, Rua Silvio Lima, Coimbra, Portugal \\ e Department of Micro- and Nanotechnology, Technical University of Denmark (DTU), Ørsteds Plads Bygning 345Ø, Kongens Lyngby 2800, Denmark \\ ${ }^{\mathrm{f}}$ Department of Life Sciences, Cattinara Hospital, University of Trieste, Strada di Fiume 447, 34100 Trieste, Italy \\ ${ }^{g}$ Department of Engineering and Architecture, University of Trieste, Via Valerio 6, 34127 Trieste, Italy \\ ${ }^{\mathrm{h}}$ Chemistry Department, Università di Torino, Via Giuria 7, 10125 Turin, Italy
}

\section{A R T I C L E I N F O}

\section{Keywords:}

Bioactive molecule delivery

Micro/nanocarriers

Hydrogels

Liposomes

Carbon nano materials

\begin{abstract}
A B S T R A C T
Over the past ten years, the global biopharmaceutical market has remarkably grown, with ten over the top twenty worldwide high performance medical treatment sales being biologics. Thus, biotech R\&D (research and development) sector is becoming a key leading branch, with expanding revenues. Biotechnology offers considerable advantages compared to traditional therapeutic approaches, such as reducing side effects, specific treatments, higher patient compliance and therefore more effective treatments leading to lower healthcare costs. Within this sector, smart nanotechnology and colloidal self-assembling systems represent pivotal tools able to modulate the delivery of therapeutics. A comprehensive understanding of the processes involved in the selfassembly of the colloidal structures discussed therein is essential for the development of relevant biomedical applications.

In this review we report the most promising and best performing platforms for specific classes of bioactive molecules and related target, spanning from siRNAs, gene/plasmids, proteins/growth factors, small synthetic therapeutics and bioimaging probes.
\end{abstract}

\section{Introduction}

The application of emerging nanotechnology to biomedical and pharmaceutical research allowed real progresses in the development of temporal and site specific drug delivery, leading to a new field of research defined as nanomedicine which nowadays is one of key fields of research [1]. Such a breakthrough was supported by the advanced scientific knowledge and technological development of different types of systems, such as carbon nanomaterials (fullerenes, nanotubes) [2], polymeric carriers (micelles, niosomes, nanoparticles, nanogels and macrogels) and lipid-based nanosystems (lipid nanovesicles, cubosomes and solid lipid nanoparticles) [3].

The use of colloidal delivery systems proved to be an efficient approach to improve the bioavailability and pharmacokinetics of small therapeutic molecules; hereby we describe the most recent advances in the field, with particular focus on the most suitable system depending on the desired bioactive molecule to be delivered.

\section{Hydrogels and colloidal structures for drug delivery}

Hydrogels can be defined as coherent systems composed by a threedimensional fibrous network, usually of polymeric origins, containing a large amount of aqueous phase, which cannot dissolve the network due to the presence of interconnections, called crosslinks [4]. Interestingly, these systems are able to host a remarkable amount of the aqueous phase (the solid network volume fraction can be lower than $1 \%$ ), whereas showing rheological-mechanical properties closer to solids rather than to liquids [4], thus mimick living tissues [5]. Hydrogels can be classified according to the nature of the crosslinks, their origin, composition, charge and configuration [6]. From a crosslinking point of

\footnotetext{
* Corresponding author at: Nano Carbon Materials Research Lab, Istituto Italiano di Tecnologia (IIT), Via Morego 30, 16163 Genova, Italy.

E-mail address: silvia.giordani@iit.it (S. Giordani).
} 


\section{WEAK CROSSLINKS}

A) Topological entanglements

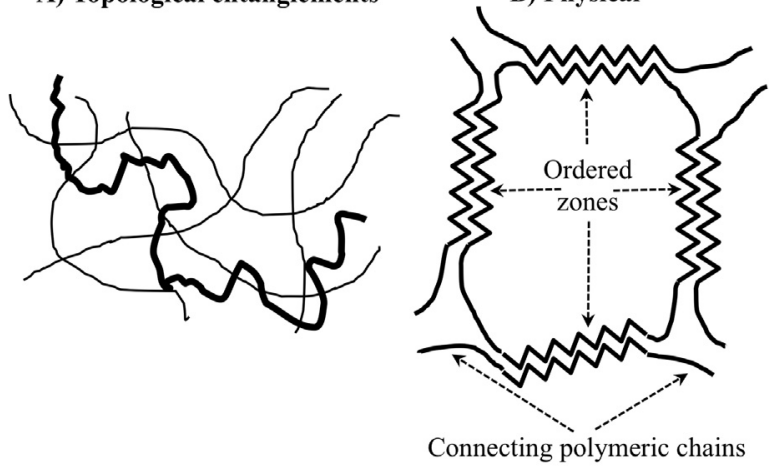

STRONG CROSSLINKS

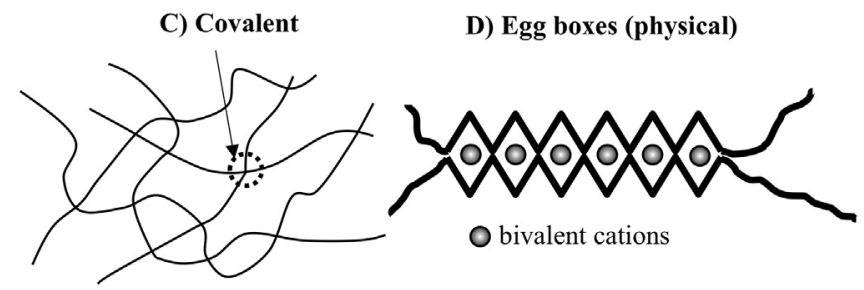

Fig. 1. Representative examples of chemical and physical crosslinks occurring in hydrogels. Based on the crosslinks nature, hydrogels can be defined as physical or chemical. In the first case, crosslinks are weak and are due to either polymer chains topological entanglements (A) or weak physical interactions (B) such as H-bonds, ionic, Coulombic, van der Waals, dipole-dipole and hydrophobic interactions. Conversely, in the case of chemical crosslinks, crosslinks between chains are strong and permanent (C-D, covalent bonds).

Adapted from [4].

view, hydrogels can be chemical or physical. In chemical hydrogels, crosslinks between different chains (fibers) are strong, permanent and punctual, due to covalent bonds. Conversely, physical hydrogels are characterized by either chains topological entanglements (spaghetti-like configuration, Fig. 1) or physical interactions (this being typical of polysaccharides such as glucans and xanthan) such as H-bonds, ionic, Coulombic, van der Waals, dipole-dipole and hydrophobic interactions.

Additional junctions can occur, with long chain segments departing from the ordered junction zones towards further chains, generating a polymeric three-dimensional network. Physical interactions are often transient, with non-strong bonding points, able to lead to a network characterized by a constant average crosslink density (i. e. moles of crosslinks per gel unit volume) and a time dependent spatial distribution of crosslinks. Thus, network meshes configure as a dynamic equilibrium, due to chains segments size and related Brownian motions, being the average mesh number and dimension constant [4,7]. Ordered zones formation is favored/hindered by environmental conditions such as temperature and ionic strength [8]. For instance, agarose undergoes a thermo-reversible gelation process occurring when hot solutions are cooled below $\sim 40{ }^{\circ} \mathrm{C}$. In the hot state, agarose chains appear to behave as stiffened coils whereas, after cooling, a particularly extensive re-organization takes place, resulting in a hydrogel aggregation, at very low polymer concentrations $(\geq 0.1 \% w / \mathrm{w})$ [9]. Physical crosslinks are usually associated with mechanically weak gels, except for $e . g$., the case of alginates, where a strong physical hydrogel arises. Alginates are linear polymers of vegetal or bacterial origin containing $\beta$-D-mannuronic (M) and $\alpha$-L-guluronic (G) acid [10], where the addition of different cations, such as $\mathrm{Ca}^{2+}, \mathrm{Cu}^{2+}, \mathrm{Ba}^{2+}$ and $\mathrm{Sr}^{2+}$, can induce gelation. These cations bind to stretches of guluronic acid residues within the polysaccharide chain, leading to the formation of junctions, which physically hold together the polysaccharide chains in a 3D continuum according to the egg-box model (see Fig. 1). Pectins are another outstanding example of polysaccharides leading to strong physical hydrogels, triggered by divalent cations, although with some changes connected to the existence of neutral sugars in the chains (that should hinder inter-chain association) and the methylation of some galactunorate residues (that do not contribute to the electrostatic ion binding). Pectin is contained in the primary cell walls of terrestrial plants, thus it is an important polysaccharide that allows primary cell wall extension and plant growth. Pectin polymers are widely employed for industrial purposes as gelling agents in food, stabilizers in fruit juices and milk drinks and as filling in medicines [10,11].

With reference to their origin, hydrogels can be natural or synthetic. Among the plethora of natural hydrogels, those based on agar, collagen, chitosan, alginate, hyaluronic acid, gelatin, fibrin and polysaccharides (animal, vegetal and microorganisms origin [12]) are most represented [13]. Conversely, D,L-lactide-co-glycolide (PLGA), polyamidoamine (PAMAM), poly(caprolactone-co-ethylethylene phosphate) (PCLEEP) and poly(N-vinyl-2-pyrrolidone) PVP can be included in the synthetic class.

For homopolymeric hydrogels, the network is formed towards a polymer constituted by a single species of monomer, whereas in copolymeric hydrogels two or more different monomer species compose the chains of the polymeric network. Finally, interpenetrating polymeric hydrogels (IPN) are made up of two (or more) independent cross-linked synthetic and/or natural polymeric chains [14].

Hydrogels can be categorized depending on their charge features, as nonionic (neutral), ionic (anionic or cationic), amphoteric electrolyte (ampholytic) containing both acidic and basic groups, zwitterionic (polybetaines) containing both anionic and cationic groups in each structural repeating unit. From a configuration point of view, they can be classified as amorphous, semicrystalline (a mixture of amorphous and crystalline phases) and crystalline [6].

Any technique that allows the formation of bonds between polymeric chains can lead to the formation of hydrogels. At this purpose, chemical reaction, ionizing radiations, physical interactions (e.g. entanglements and electrostatics) and crystallite formation can be used. Moreover, hydrogels can be obtained thanks to polymerization techniques, including bulk, solution, and suspension polymerization [6]. However, an aqueous environment and room temperature are mandatory to perform a safe crosslinking procedure, in order to obtain hydrogels from a solution containing the polymer and hydrophilic drugs that can easily undergo denaturation such proteins, peptides and drugs based on nucleic acid (NABDs). For example, these requirements are perfectly accomplished by the ionic gelation of polysaccharides such as alginates and galacturonic [15]. Ionic gelation can also occur in the case of polycations with an anion as the crosslinker. Specifically, the ionic interaction between chitosan (polycation) and the trivalent negatively charged glycerol phosphate was shown to induce hydrogel formation [16].

Both macroscopic and micro/nanoscopic properties of hydrogels play an important role in biomedical applications. It has been recently demonstrated that, in three-dimensional culturing, the (macroscopic) viscoelastic properties of hydrogels used as substitutes of natural extracellular matrix (EM) can affect cells behavior in terms of spreading, proliferation and differentiation. Chaudhuri and co-workers [17] demonstrated that the osteogenic differentiation of mesenchymal stem cells (MSCs) strictly depends on the viscoelastic properties of the alginates hydrogels used as substitute of EM. In detail, mesenchymal stem cells form mineralized, collagen-1-rich matrix similar to bone only when they are in contact with highly elastic hydrogels.

On the other hand, when hydrogels are created to release active agents, the mesh size distribution of the three-dimensional network (nanoscopic property) represents a relevant characteristic. Indeed, mesh size distribution is a key parameter ruling the release kinetics of an embedded drug and it can be essential to protect hydrogel cargo (drug, cells and so on) by external factors such as enzymes and the immune system agents. An outstanding example is represented by 
hydrogel based implantable systems, as well as immunoisolant membranes, which serve to protect encapsulated pancreatic cells (aimed at the production of insulin) from antibodies [18].

In terms of release mechanisms, hydrogels drug depot can be controlled by physical, physicochemical and system related strands [19]. Swelling/shrinking processes are related to physical phenomena, whereas erosion, drug dissolution (recrystallization), drug transport (by diffusion and convection) and drug interaction throughout the matrix structure constitute the physicochemical phenomena. System related mechanisms depend on the initial drug distribution and concentration inside the hydrogel, hydrogel geometry (cylindrical, spherical, etc.) and size distribution in the case of polydispersed ensembles of hydrogels.

The swelling/shrinking process occurs upon variation of external factors (temperature and $\mathrm{pH}$, more frequently), inducing a new equilibrium condition or when the dry hydrogel is in contact with an aqueous environment. The abovementioned process relies on the chemical potential difference between the water inside and outside the hydrogel [20].

Hydrogel erosion can be ruled out by chemical and/or physical factors. Erosion can be defined as peripheral or heterogeneous, when it affects only hydrogel surface. On the other hand, bulk or homogeneous erosion involves the whole hydrogel volume [21]. Chemical erosion is due to hydrolytic/enzymatic degradation of polymeric chains, while physical erosion depends on chains disentanglement due to the hydrodynamic conditions of the external aqueous environment.

Stability restrictions often require hydrogels storage in the dry status. In such a case, drug release will begin as soon as an external aqueous fluid diffuses towards the polymeric network and a key step can be represented by the drug dissolution over the water permeating the network. When metastable bioactive molecules like polymorphs, amorphous or nano-crystalline drugs are present in the dry hydrogel, the dissolution process may correlate with recrystallization which leads to the formation of a new, more stable, drug crystallographic organization induced by the contact with the absorbed water [22].

Bioactive molecule depot and mobility towards colloidal networks can be strongly affected by the hydrogel mesh size distribution, as well as by the drug physical and chemical interactions with the 3D polymeric network [23]. For instance, drug adsorption/desorption phenomena may be due to electrostatic interactions, such as charged polypeptides and antibiotics in collagen matrices [24]. Moreover, bioactive molecule delivery can be influenced and driven by hydrogen bonds [25], lipophilic [26], as well as non-covalent interactions among imprinted polymeric networks and template molecules that need to be recognized in a physiological environment [27].

Colloidal and hydrogel frameworks are key structures for several bioactive molecule controlled delivery, with a specific application for Nucleic Acid based Drugs (NABDs) release.

NABDs are constituted by short sequences of either DNA or RNA, including antisense oligonucleotides, decoys oligonucleotides, aptamers, triple helix forming oligonucleotides, DNAzymes, Ribozymes, small interfering RNAs (siRNAs) and micro interfering RNAs (miRNAs) [12]. Despite their massive therapeutic potential towards different hyper-proliferative diseases [28], their daily clinic application is still very limited because of their rapid degradation by several enzymes, such as blood and cellular nucleases [29]. Moreover, as detailed in the next section (Section 3.2), considering that both NABDs and cellular membranes are negatively charged, crossing the cellular membrane represents the core drawback, due to electrostatic repulsion. Thus, delivery of naked NABDs cannot lead to exploit their therapeutic activity. Delivery vectors can be divided into three classes, based on their size [30]: nano, micro and macro scales vectors. Nanoscale vectors are represented by polycationic polymers or lipids that self-assemble with NABDs to form polyelectrolyte complexes (poly- or lipo-plexes, respectively, as detailed in Section 3). Microscale vectors can be outlined, for example, as hydrogels entrapping the poly- or lipo-plexes. Macroscale vectors are three dimensional matrices (such as hydrogels) that can host microvectors containing, in turn, poly- lipo-plexes to give rise to a chimeric system [31]. An outstanding example of chimeric system has been proposed by Knipe and co-workers [32], who dealt with the oral release of siRNA targeting TNF- $\beta$, an inflammatory cytokine that is a clinical target of inflammatory bowel diseases. The chimeric delivery system consists of micro-gels (size $<30 \mu \mathrm{m}$ ) composed of poly(methacrylic acid-co-N-vinyl-2-pyrrolidone) (PMANVP) crosslinked with a trypsin - degradable peptide linker. PMANVP micro-gels contained siRNA-loaded polycationic nanogels (2-(diethylamino)ethyl metacrylate) (size $\approx 120 \mathrm{~nm}$ ) that proved to guarantee siRNA protection and cells transfection. PMANVP matrix was designed to collapse around

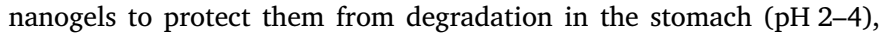
while PMANVP swelling in the small intestine environment at pH 6-7.5, allowed matrix degradation, due to the uptake of intestinal fluids containing trypsin. Consequently, nano-gels could be released and internalized by cells, resulting in a considerable TNF- $\beta$ knockdown in a murine macrophage model.

Chimeric systems can be used for the systemic delivery of NABDs too. Indeed, following injection administration, the NABD-vector complex is supposed to circulate towards capillaries and microvasculature structures (blood vessel diameter $<100 \mu \mathrm{m}$ ), cross the blood vessel wall and finally reach the target cells. Thus, the NABDvector complex is required to move radially towards the vessel wall, through a margination mechanism. D'Apolito and co-workers [33] experimentally showed that margination is due to red blood cells and NABD-vector complexes interaction. The mentioned process is possible whether complexes size spans in diameter range $>1 \mu \mathrm{m}$, with $3 \mu \mathrm{m}$ vectors better marginating than $1 \mu \mathrm{m}$ sized particles. Accordingly, nano-sized complexes have poor chances to get to the vessel wall. However, nanocomplexes embedding into micro-vectors allows the overall structure to reach blood vessel wall. Therein, nano-vectors can be released, for example, by micro-vectors surface or bulk erosion.

\section{3. siRNA delivery}

\subsection{Small interfering RNAs}

During last years, the most commonly tested NABDs have been siRNAs. These short double stranded RNA molecules approximately 22 nucleotides in length, are mostly of exogenous origin, being generated from invasive nucleic acids such as viruses and transposons [34]. With reference to the mechanism of the two siRNAs filaments (Fig. 2A), mostly the antisense strand is uptaken by the cytoplasmic RNA-induced silencing protein complex (RISC). The antisense strand drives RISC to a target RNA via a perfect sequence complementarity to the target. Following binding, RISC mediates the degradation of the target RNA thus resulting in the downregulation of gene expression. It is possible to take advantage of this mechanism of action to generate siRNAs able to target RNAs causing disease, as shown in many other works [35-38].

\section{2. siRNA delivery problems}

Despite the great siRNA therapeutic potential, their practical use is limited by their chemical nature. Following systemic administration, siRNAs encounter blood nucleases, which can rapidly degrade their nucleic acid structure (Fig. 2B).

Moreover, siRNAs tend to be removed by the reticulo-endothelial system, by kidney filtration [39] and, depending on the sequence, to activate the innate immune response [40]. Additional barriers to siRNAs cellular uptake are represented by the vessel wall and the cellular membrane, due to the electrostatic repulsion between the negatively charged phosphate groups present on siRNAs and the negatively charged surface of cellular membranes. Moreover, siRNAs cellular uptake is difficult due to its hydrophilic nature of that does not enhance the crossing of the hydrophobic layer of the cell membranes.

The fraction of siRNAs that succeed crossing the cell membrane, 

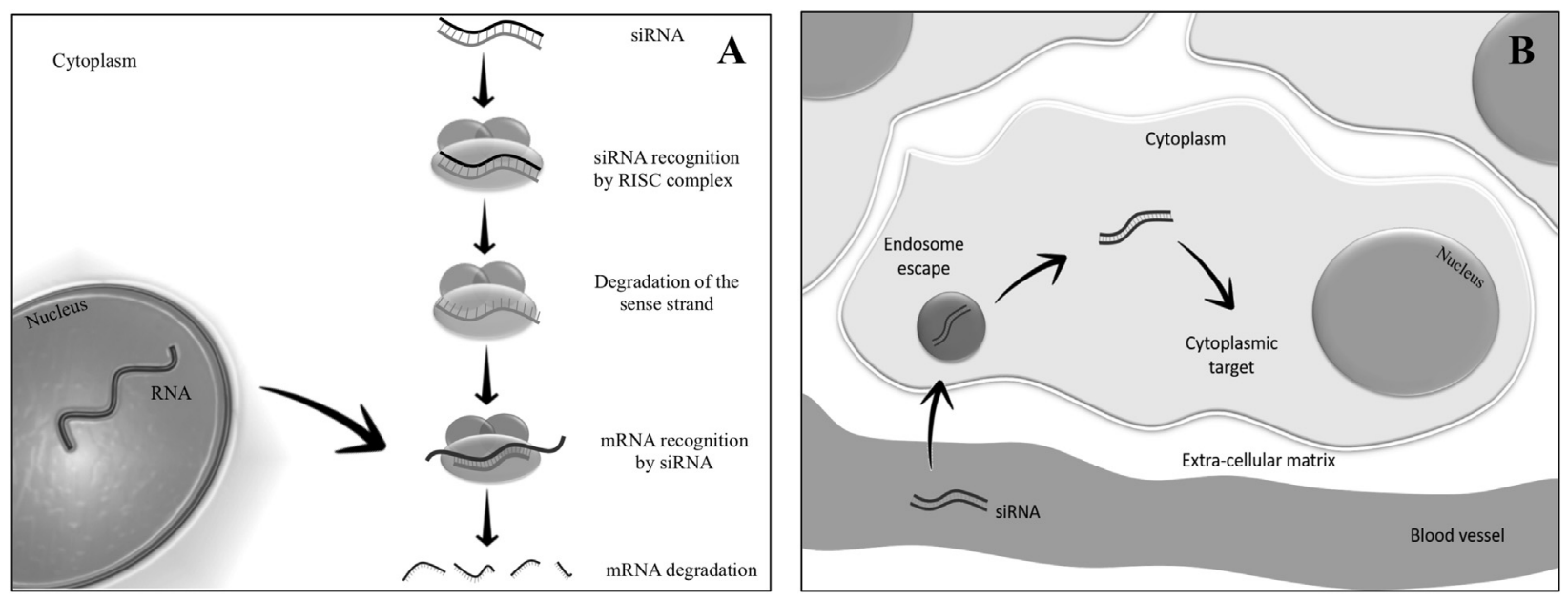

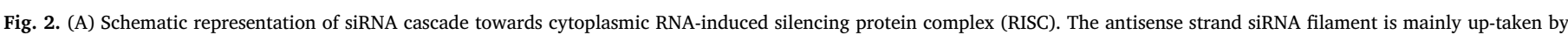

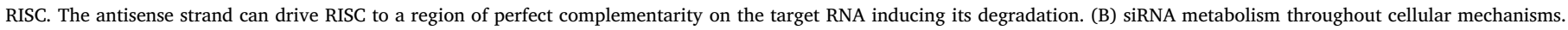

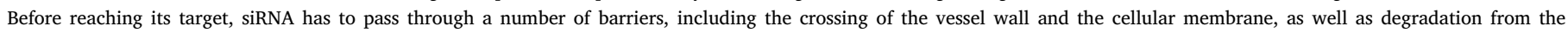
extracellular/cellular nucleases and endosomes.

further will face with cytosolic nucleases and then can reduce their amount. Finally, siRNAs experience the problem of cellular trafficking [41]. Depending on the mechanism of cellular internalization, siRNAs can be uptaken by endosomes. At this stage, when confined into these intracellular vesicles, siRNAs cannot reach their targets and thus to exert any biological effect. Based on the abovementioned considerations, the administration of naked siRNA results in negligible therapeutic effects.

\subsection{Strategies to minimize siRNA delivery issues}

Two main strategies can be employed in order to minimize the delivery issues of exogenous siRNAs. The first one consists of a chemical modification of siRNA structure to make these molecules more resistant to degradation. The second strategy is based on the siRNA complexation with synthetic engineered vectors to effectively bind and protect siRNAs and to allow their delivery to the target cells [42]. Frequently, the two strategies are used in combination, even though some chemical modifications may affect siRNA effectiveness.

The choice of the optimal delivery materials is not a trivial task $[12,34,42,43]$, with the net superficial charge of the delivery carrier/ siRNA complex playing a key role. Anionic and cationic complexes usually show good solubility/stability in the physiological environment, despite they exhibit some drawbacks. Anionic complexes cannot transfect cells per se, due to the electrostatic repulsion with the negatively charged cell membrane. Conversely, cationic complexes bind to cell membrane towards strong electrostatic interactions, leading to nonspecific cellular uptake and cell toxicity if the positive charge is not optimal [44]. On the other hand, neutral complexes tend to associate in the physiological environment, resulting in a limited solubility. Thus, the development of optimal delivery carriers requires a careful evaluation of different parameters such as the surface charge density.

Besides providing for siRNA protection and targeting, the ideal delivery vector should be able to allow efficient extravasation of the siRNA. This feature is crucial for siRNA-vector complexes systemic administration. Therein, the size of siRNA-vector complexes plays a relevant role, as abovementioned for NABDs. It has been recently showed that particles in the 1-3 $\mu \mathrm{m}$ diameter range [33] tend to localize closer to the endothelial layer (margination effect) of the vessel, compared to smaller particles. Thus, $1-3 \mu \mathrm{m}$ particles localize closer to the vessel fenestration, being more susceptible to extravasation compared to smaller particles, which, alternatively, tend to localize in the middle of the vessel. Despite this advantage, it should be considered that particles bigger than $0.2 \mu \mathrm{m}$ are readily scavenged non-specifically by monocytes and the reticuloendothelial system, thus not be efficiently uptaken by cells $[45,46]$. A possible solution may rely on the preparation of microparticles able to undergo a disassembly, upon extravasation, originating nano-metric particles. As previously introduced, the preparation of micro-sized delivery systems containing nano-metric particles can be included within the class of delivery strategies known as "chimeric systems" [30,47]. This approach presents a dual advantage. First, micro-particles are easy to handle, to produce on large scale and to store. Secondly, nanostructures are characterized by an extremely high surface/volume ratio, with valuable drug payload efficiency. Polycationic polymers and lipids are most commonly employed to form nanoscale vectors. On the other hand, microscale vectors entrapping nanoscale vectors usually consist of two/three dimensional scaffolds or matrices mainly made by polymers.

The following sections will focus on the presentation of strategies most commonly used to prepare nanoscale vectors, i.e. lipid and polymers nanoparticles [48-52].

\subsubsection{Lipidic nanoparticles}

Lipid-based nanoparticles (LNPs) have been extensively used as delivery systems for drugs and siRNAs, showing promising results both in vivo and in vitro. LNPs have appropriate delivery characteristics as their structure mimics cellular membranes, thus enhance the fusion with the target cell. Moreover, LNPs can be easily loaded with several cargo molecules.

3.3.1.1. Liposomes. Liposomes are spherical self-assembled vesicles, deriving from synthetic or natural phospholipids containing aqueous compartments (Fig. 3A). The polar heads of phospholipids interact with the hydrophilic environment thus stabilizing lipids structure; in contrast, the long phospholipid chains interact each other, forming lipid layers in aqueous solution. Liposomes can be structured as unilamellar or multilamellar lipid bilayers. Due to the amphiphilic nature of phospholipids, these molecules can generate hydrophilic and hydrophobic compartments in the same system, thus allow for both hydrophobic and hydrophilic molecules (siRNA) hosting. Liposomes present a low immunogenicity and are biodegradable [53].

3.3.1.2. Cationic liposomes. Positively charged (cationic) liposomes are most frequently used for siRNA delivery. They can electrostatically 
A) Liposome

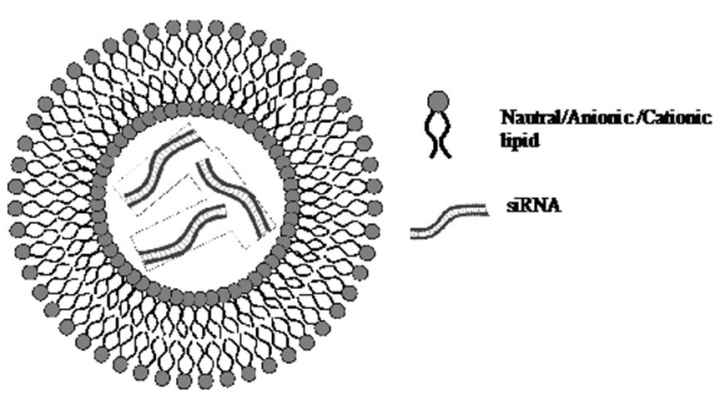

C) Lipidoid

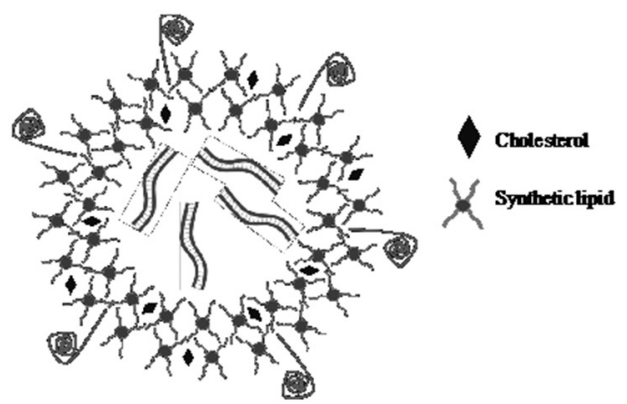

B) SNALP

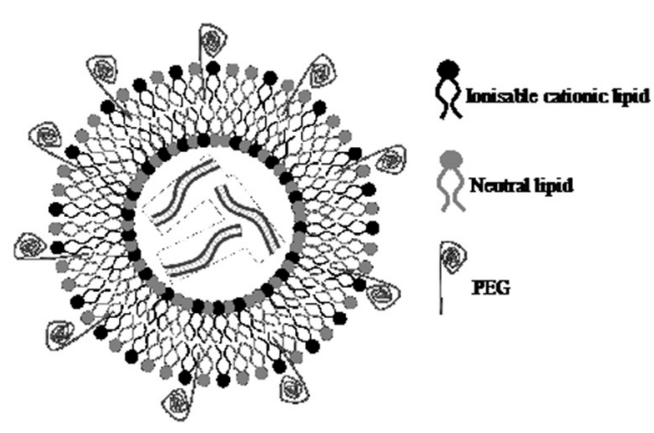

D) Solid Lipid Nanoparticle

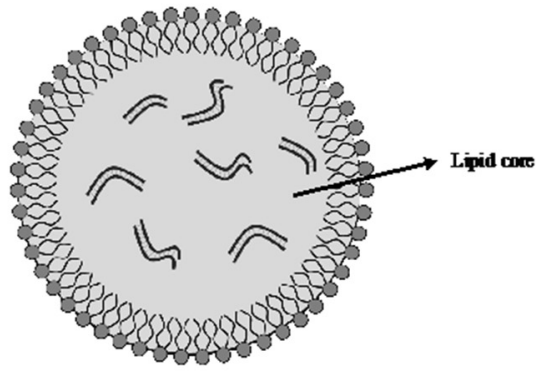

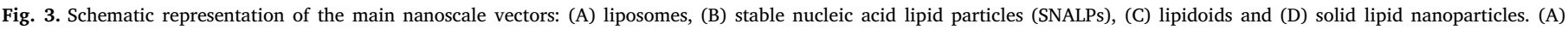

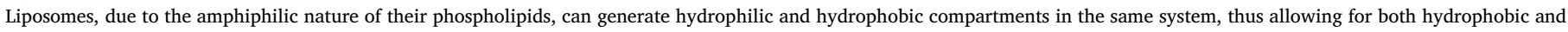

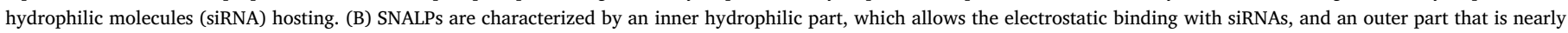

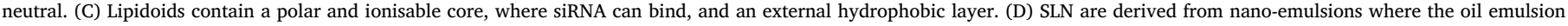
component is replaced by a solid lipid dispersed in a surfactant solution; chemical modifications are required to allow the incorporation of the hydrophilic siRNA into SLN.

interact with the negatively charged siRNAs and allow an efficient molecule loading [43,54]. Additionally, cationic liposomes can easily interact with the negatively charged cell membrane. Sometimes, to further improve the ability to integrate with cell membrane,

they are added with non-cationic lipids, such as DOPE (dioleoylphosphatidylethanolamine) and DSPC (1,2-Distearoyl-snglycero-3-phosphocholine). The positive surface charge is favourable for siRNA binding, but it can cause the side interaction with negatively charged serum protein such as albumin. In such a case, the negatively charged serum protein can displace siRNA from the positively charged liposome, thus significantly reducing the amount of siRNA delivered to the target tissue. The modification of liposomes with the neutral lipids such as cholesterol can contribute to overcome this limitation [55]. Moreover, cholesterol can be used also to bind other molecules such as polyethylene glycol (PEG), a polymer able to improve the delivery properties both in vitro and in vivo [53].

There are different types of cationic liposomes for siRNA delivery, such as monovalent cationic liposomes and multivalent cationic liposomes. For instance, N-[1-(2,3-dioleyloxy) propyl]- $, N, N$-trimethylammonium chloride (DOTMA), 1,2-bis(oleoyloxy)-3-(trimethylammonio)-propane (DOTAP) and $3 \beta-\left[\mathrm{N}-\left(\mathrm{N}^{\prime} \mathrm{N}^{\prime}\right.\right.$-dimethylaminoethane) carbamoyl]cholesterol (DC-Chol) are monovalent cationic lipids, characterized by a high in vitro transfection efficiency [56].

Multivalent cationic lipids (MCLs), synthetized from monovalent cationic lipids, exhibit an increased positive charge compared to monovalent cationic lipids. However, they tend to be more toxic than monovalent cationic lipids [57]. A widely used MCL transfection agent is Lipofectamine (2,3-dioleyloxy- $\mathrm{N}$-[2(sperminecarboxamido)ethyl]$\mathrm{N}, \mathrm{N}$-dimethyl-1-pro-paneammonium trifluoroacetate and dioleoyl-hosphatidylethanolamine in ratio 3:1 (DOSPA/DOPE 3/1)), which contains the multivalent cationic lipid DOSPA. This mixture of lipids forms multilayers structures with the siRNA being embedded between adjacent lipid bilayers [58]. Lipofectamine can efficiently deliver siRNAs to a broad range of cells, although they exert a significant unspecific cell toxicity. For example, siRNAs directed against the mRNAs of the cell cycle promoting genes cyclin E and E2F resulted in a relevant inhibition of smooth muscle cells (SMC) proliferation. As SMC aberrant proliferation is a key event in many coronary artery diseases [46,59], the mentioned approach has the potential to minimize this pathological event. Per se, the cationic liposome-mediated delivery of siRNAs to the coronary wall is not sufficient to guarantee an effective delivery. In this case, the delivery of siRNA-cationic liposomes entrapped into gel matrix has been proposed, in order to prevent the rapid wash out of siRNA complexes due to blood flow [60].

3.3.1.3. Stable nucleic acid lipid particles (SNALPs). Recently, stable nucleic acid lipid particles (SNALPs) have been developed for siRNAs delivery (Fig. 3B) [43]. SNAPLs are constituted by a lipid bilayer containing the ionisable cationic lipid 1,2-dilinoleyloxy-3dimethylaminopropane (DLinDMA) or 2,2-dilinoleyl-4-(2dimethylaminoethyl)- [1,3]-dioxolane (DLin-KC2-DMA) in the inner part, to allow the binding with siRNAs. Moreover, they contain PEG, which can stabilize the complex and a neutral lipid, like DSPC or cholesterol, which enhances the endosomal escape of the SNALP/siRNA complex [61]. Thus, the structure of SNALPs is characterized by an inner hydrophilic part, which allows the electrostatic binding with siRNAs, while the external surface is nearly neutral. Appropriate modifications in SNALPs, for example in the type and ratio of the different components, can extend the circulation time and minimize complement system activation [53].

SNALPs delivery systems were for example used to encapsulate a 
COP9 Signalosome Subunit 5 (CSN5) siRNA [62]. CSN5 is the catalytic center of the COP9 Signalosome that is involved in the control of proteolysis via the ubiquitin proteasoma pathway. CSN5 seems also to act as transcriptional coactivator for MYC and TGF $\beta 1$, gene products involved in the control of proliferation, apoptotic cell death and hepatocellular carcinoma (HCC) progression. This delivery system significantly inhibited tumor growth in an orthotopic mouse model of HCC [62].

3.3.1.4. Lipidoid nanoparticles. Lipidoid nanoparticles are made up of synthetic lipids obtained by the chemical combination of alkyl-amines with alkyl-acrylates containing carbon chain tail of variable length [63] (Fig. 3C). The particles containing the lipidoid have a polar and ionisable core, surrounded by hydrophobic carbon tails. The particles can also contain cholesterol and PEG, two types of molecules that can enhance particles stability and delivery efficiency [58]. In addition, their simple synthetic protocol allows the production of a considerable amount of different particles, which can be tailored to any different delivery purpose. For example, a siRNA embedded into lipidoid-based nanoparticles was used to downregulate $\beta 1$ and $\alpha \nu$ integrin subunits in the hepatocytes of a xenograft mice model of HCC [64]. $\beta 1$ and $\alpha \nu$ integrins are relevant extracellular matrix receptors involved in many cellular processes. Moreover, they play critical biological roles both in normal liver and in HCC tumor cells. Integrin silencing had, as major outcome, an extended morbidity-free survival of HCC tumor-bearing mice [64].

3.3.1.5. Solid-lipid nanoparticles. Solid-lipid nanoparticles (SLN) are novel siRNAs carriers derived from nano-emulsions where the oil emulsion component is replaced by a solid lipid dispersed in a surfactant solution (Fig. 3D). The loaded molecules are incorporated in the solid lipophilic matrix. SLN, solid at room temperature, are stable, non-cytotoxic, present a large surface area and can efficiently protect the encapsulated molecules [65]. However, they show some disadvantages such as the low molecules loading capacity and the possible expulsion of the incorporated molecules during storage. The chemical nature of the solid-lipid matrix determines the loading capacity, as well as the type of molecule to be loaded [66]. SLN usually contain a combination of triglycerides, partial glycerides, fatty acids, steroids and waxes. In order to decrease cytotoxicity and immune responses, SLN can be prepared using physiological lipids present in the natural low density lipoprotein (LDL) such as cholesteryl ester, triglyceride, cholesterol, DOPE, and DC-cholesterol [67]. Lipids found in the natural high-density lipoproteins (HDL) represent an alternative. Overall, chemical modifications are required to allow the incorporation of the hydrophilic siRNA [68]. An example of siRNA delivery by SLN has been reported by Jin J. et al. [69]. Considering that c-mesenchymalepithelial transition (c-MET) is a signalling receptor for hepatocyte growth factor, SLN were reconstituted from natural components of protein-free LDL and further conjugated to PEGylated c-Met siRNA. Inappropriate c-Met activation relates to different form of human tumours including glioblastomas (GBMs). The latter is the most frequent and malignant form of brain tumor, with limited treatment options due to the blood-brain barrier. In orthotopic U-87MG xenograft tumor model of GBM, intravenous administration of the complex significantly inhibited c-Met expression and suppressed tumor growth. No major signs of systemic toxicity were observed in mice.

\subsubsection{Polymers}

Polymers are solid and biodegradable molecules widely employed for siRNA delivery. Many different polymers have been tested so far, such as Chitosan (CH), Polyethylenimine (PEI), PEG, $\alpha, \beta$-poly(N-2-hydroxyethyl)-D,L-aspartamide and Inulin-derived polymers.

$\mathrm{CH}$ is a polymer characterized by low toxicity, high biocompatibility and biodegradability [12]. $\mathrm{CH}$ is derived from chitin, has a carbohydrate backbone characterized by two types of repeating residues, 2- amino-2-deoxy-glucose (glucosamine) and 2- $\mathrm{N}$-acetyl-2-deoxy-glucose (N-glucosamine), linked by (1-4)- $\beta$-glycosidic linkage. Furthermore, $\mathrm{CH}$ has a positive charge, due to the presence of positively charged amino groups present in its structure, thus, it can easily and efficiently bind negatively charged molecules such as siRNAs. On the other hand, $\mathrm{CH}$ has some disadvantages such as the low transfection efficiency and low solubility, which can be prevented through the conjugation with other molecules such as PEI, PEG, Poly (amidoamine) (PAMAM) dendrimers. As an alternative, $\mathrm{CH}$ physicochemical and biological properties can be improved by modulating the deacetylation rate and/or modifying the molecular weight [70]. In order to solve $\mathrm{CH}$ drawbacks, another approach involves the use of synthetic polymers (e. g. PEI). Such a polymer contains repeating units composed of an amine group and two aliphatic $\mathrm{CH}_{2}-\mathrm{CH}_{2}$ spacers. It can exist both in linear and branched forms. It is one of the most used cationic polymers, even though it tends to be more toxic than natural polymers [71]. Usually, PEI with high molecular weight has higher cytotoxicity compared to low molecular weight PEI, despite its transfection effectiveness. To decrease toxicity, PEI can be chemically modified, such as the addition of hydrophilic and hydrophobic segments or cell/tissue-specific ligands [72]. As previously described for $\mathrm{CH}$, PEI easily binds negatively charged molecule such as siRNAs. Moreover, PEI favours siRNA escape from endosomes, thanks to its "proton sponge effect" [73]. Finally, liposome coating with PEI results in an increased liposomes circulatory time [74], thus improving systemic delivery.

PEG is a polymer of ethylene oxide monomers considered to be nontoxic and safe $[75,76]$. It is widely used because of its solubility in aqueous environment and organic solvents. PEG addition (PEGylation) to deliver particles reduces toxicity and stabilizes the particles, as it is the case of PEGylated liposomes where PEG is added into the liposomal bilayer [77]. PEG is also used to bind specific ligands to be fixed on the liposome surface [78].

For instance, a copolymer based on $\alpha, \beta$-poly(N-2-hydroxyethyl)-D,Laspartamide (PHEA) bearing positively chargeable side oligochains, with diethylamino ethyl methacrylate (DEAEMA) as monomer has been developed [79]. The PHEA-DEAEMA polymer was able to efficiently form complexes with siRNA. Moreover, it demonstrated to be stable in liquid fluids and protected siRNA without being significantly cytotoxic in the HCC cell line HuH-7. The copolymer was loaded with an anti E2F1 siRNA and tested in JHH6. E2F1 is a transcription factor promoting cell proliferation that plays an important role in the growth of HCC cells [28]. A significant down regulation of JHH6 cell growth was observed, in addition to a reduction in siRNA target.

As an alternative polymer for HCC cell delivery, a siRNA delivery system based on inulin (Inu) was reported. This is an abundant and natural polysaccharide functionalized for the specific requirements of siRNA delivery by conjugation with diethylenetriamine (DETA) residues (Inu-DETA) [80]. Inu-DETA copolymers can effectively bind siRNAs, are highly biocompatible and, in the HCC cell line JHH6, can effectively deliver functional siRNAs. The Inu-DETA particles loaded with a siRNA anti E2F1 [28], effectively reduced the levels of E2F1 and the proliferation of JHH6. Moreover, the uptake and trafficking mechanisms, mainly based on micropinocytosis and clatrin mediated endocytosis, allowed a triggered release of siRNA within the cytoplasm of JHH6.

The abovementioned examples clearly indicate how cationic copolymers can bind siRNAs via electrostatic interaction, thus forming complexes able to promote cellular uptake and significantly improve the half-life. However, polymers can be also used in the form of micelles for delivery purposes. Micelles are spherical structures containing simple units (unimers) oriented with the hydrophobic tail towards the inner part of the micelles and the hydrophilic heads against the external shell (Fig. 4). Unimers can be generated conjugating cationic polymers with stearic acid (SA), a saturated fatty acid with an 18-carbon chain. For example, $\mathrm{CH}$ polymer does not self-assembly into micelles; nevertheless, following the conjugation with stearic acid (SA), $\mathrm{CH}$ polymer 


\section{Polymeric micelle}

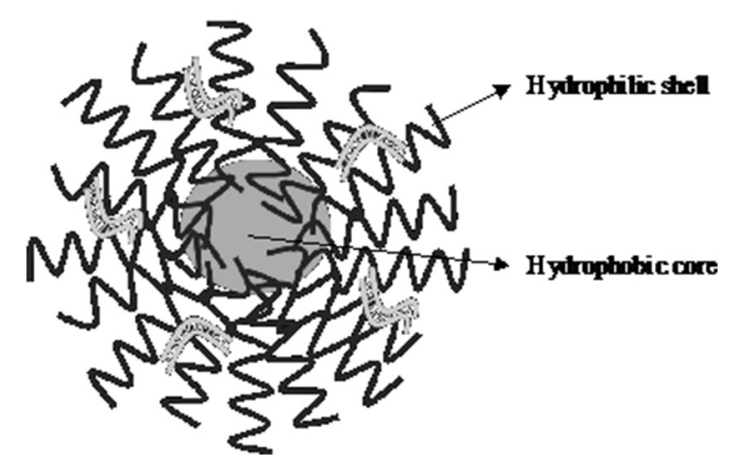

Fig. 4. Schematic representation of a polymeric micelle. Micelles are spherical structures containing simple units (unimers) oriented with the hydrophobic tail towards the inner part of the micelles and the hydrophilic heads over the external shell; siRNA can be hosted in the hydrophilic region of micelles.

can form micelles. This example demonstrates good plasticity of polymers and their derivatives to prepare siRNA delivery systems [81]. Other example of cationic polymer able to form micelles in solution is PEG and poly(propylene sulfide) [82,83].

\section{Plasmid, gene and probiotic delivery}

Considering drug-based treatments are limited to treat symptoms, gene delivery emerged as a very promising method for the treatment (or elimination) of the causes associated to a broad range of diseases related to genetic factors [84]. This approach relies on the effective delivery and transfer of genes into specific cells to alter the expression of the existing ones. Theoretically, it should either cure the disease or, at least, slowdown its progression [84]. There are two main components in the system: the carrier (i. e. gene delivery vector) and the therapeutic agent (i. e. genetic material). The delivery system should be able to carry, protect and deliver the genes in a safe and effective system to a wide range of different cells [85]. Although viral based vectors are extremely efficient carriers to deliver genes, several drawbacks associated to their high cost, difficulties in large scale production and safety issues (e.g immunogenicity, tumorigenic mutations) have driven the attention to other technological alternatives. In this context, during the last decades, a lot of attention has been focused on the development of efficient non-viral vectors for gene delivery. Despite the low efficiency compared to viral vectors, these systems present several important advantages, such as low immunogenicity, absence of endogenous virus recombination, low production cost, easy implementation in large scale $[86,87]$.

As previously discussed, within the non-viral systems class, cationic polymers have received a growing interest due to the possibility to easily tune their structure and characteristics (e.g molecular weight and composition) in order to enhance the performance of the gene delivery system [88]. The positive charges of the cationic polymers interact electrostatically with the negative charges of the gene material, leading to the formation of complexes known as polyplexes. Since the pioneer work of Vaheri and Pagamo, in 1965, that proposed the use of dextran functionalized with diethylaminoethyl groups [89], an enormous library of cationic polymers have been suggested for gene delivery, such as chitosan [90,91], poly(L-Lysine) (PLL) [92], poly(ethylenimine) (PEI) [93], poly [(2-dimethylamino) ethyl methacrylate] (PDMAEMA) [94] and poly( $\beta$-amino ester) (P $\beta A E)$ [95]. Despite branched PEI [93] $\left(\mathrm{Mw}=25,000 \mathrm{~g} \cdot \mathrm{mol}^{-1}\right)$ has been considered as the "gold standard" due to the high transfection efficiency, its high toxicity seriously compromises its use [96] (Fig. 5).

Overall, two main problems are associated to the polymer-based systems: minor efficiency due to the deficient capacity to overcome some extra- and intracellular gene delivery obstacles (e.g diffusion to the endothelial membrane, endosomal escape, unpacking among others); and cytotoxicity [97]. These issues have been mitigated using different approaches that include: the use of poly(ethylene glycol) (PEG); introduction of hydrophobic segments [97]; and the functionalization of polymers with moieties such as sugar molecules, antibodies, growth factors, etc. [87].

Despite the remarkable advances registered over the last decades on gene therapy, the levels of efficiency are very unsatisfactory to turn their clinical usage a routine. A promising approach to overcome this limitation involves the use of stimuli-responsive polymers that can change their physico-chemical characteristics upon the application of a specific stimulus. In the gene therapy area, these stimuli can be endogenous like enzyme concentration, $\mathrm{pH}$, redox potential, or exogenous such as temperature, light and ultrasounds. The remarkable feature of this class of polymers relies on the possibility to rationally adapt the physical/chemical characteristics of polyplexes during their path to maximize their efficiency. The binding capability of the cationic segment should be high to afford dense and stable polyplex, while during the unpacking step weaker bindings are required $[98,99]$. Therefore, the use of stimuli-responsive polymers can be a very effective approach to tailor the properties of polyplexes in the different environments both outside and inside the cell. Aiming to explore the potential of these smart systems, several carriers have been used in gene therapy [100-102]. PDMAEMA is a thermoresponsive and pH-responsive polymer, being one of the most used systems in gene delivery, able to easily complex with DNA [94].

Reversible Deactivation Radical Polymerization (RDRP) methods brought an outstanding toolbox of techniques that allows to synthesize tailor-made polymers with controlled composition, architecture, molecular weight and active chain-end functional groups [103]. Advances on "click" chemistry techniques [104] as 1,3-dipolar azide-alkyne cycloaddition (CuAAC) [105] and/or thiol-ene [106] reactions has opened important routes to the synthesis of novel block copolymers and in the functionalization with different moieties (e.g proteins, sugars) to well-defined polymer backbone.

Nowadays, it is possible to establish precise structure/properties relationships for the different polymers due to the ability to control their composition, structure, and functionality. Atom Transfer Radical Polymerization (ATRP) [103,107] and RAFT (Reversible Addition Fragmentation Transfer) [108-110] are the most used ones to develop block copolymers for gene delivery. Several recent reviews have highlighted the important progresses achieved with these two advanced polymerization techniques in biomedical applications and gene delivery $[111,112]$. Controlled molecular architectures in terms of chain topology [103,108] (cycles, stars, combs, brushes), composition $[103,108]$ (block, graft, alternating, gradient copolymers), and functionality are now easily accessible for most type of monomers used to afford stimuli-responsive structures. Star polymers, due to the higher ability of forming spherical polyplexes, which enhances the internalization in the cell, have received particular attention [113]. Indeed, several contributions have shown promising results for stars regarding transfection efficiency when compared to their linear or randomly branched counterparts [114-116].

The simultaneous development of the polymer synthesis strategies over the next years will allow the preparation of new block copolymers with innovative sequential addition of new monomers. Consequently, it can be easily envisaged that there will be the appearance of the new cationic block copolymers rationally designed to overcome the aforementioned limitations (e.g biological barriers) leading to broad use of non-viral vectors in clinical practice.

Surfactants, such as polymers, are excellent candidates for non-viral methods in gene delivery. As previously discussed, depending on 

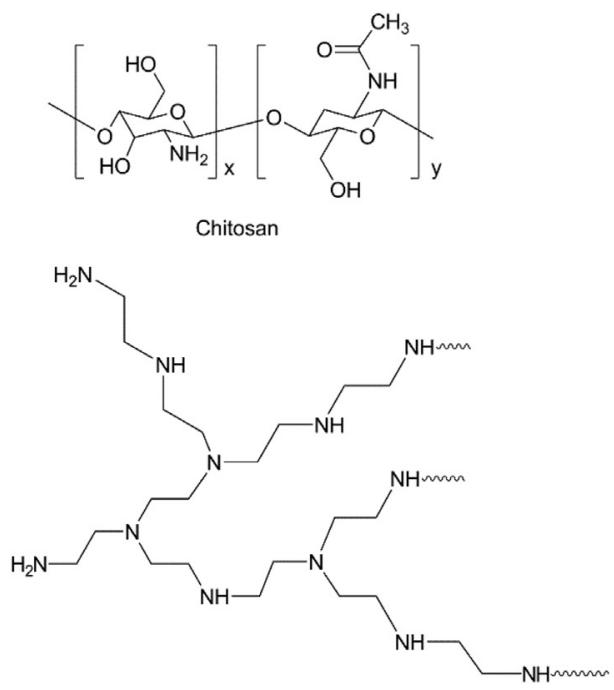

Branched poly(ethyleneimine)
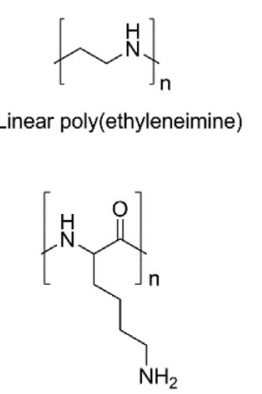

Poly(L-lysine)

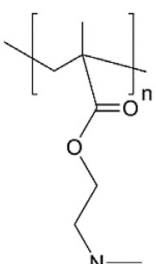

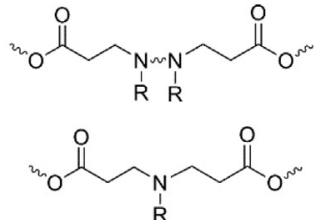

Poly( $\beta$-aminoesters $)$
Fig. 5. Schematic examples of cationic polymers used as nonviral gene delivery vectors. Chitosan is a cationic polysaccharide obtained from the alkaline deacetylation of chitin. Poly(L-lysine) is plenty of $\varepsilon$-amino groups, being able to condense genetic material. Linear poly(ethyleneimine) is composed exclusively by secondary amines and was the second gene transfection agent discovered, after poly(L-lysine). Branched poly (ethyleneimine) has primary, secondary and tertiary amines in its structure and it is considered the 'gold standard' of the gene transfection agents. Poly( $\beta$-aminoesters) are able to self-assemble genetic material and form positively charged nanoparticles. Poly(2-dimethylaminoethyl methacrylate) is composed by tertiary amines and has a transfection efficiency similar to branched poly(ethyleneimine) and Lipofectamine $^{\mathrm{TM}}$. (For interpretation of the references to color in this figure legend, the reader is referred to the web version of this article.) surfactant architecture, they can self-assembly into different structures and work as efficient nano-compartments for gene delivery [117]. For this purpose, many synthetic surfactants or lipids have been designed to increase the performance of cellular uptake, transfection efficiency [118] and to enhance the solubility of hydrophobic molecules, making them suitable for parenteral administration. An extensive number of contributions encompassing the advantages of surfactant based gene delivery systems are available in the literature [119-124].

Surfactant based nanoparticles are already been used to treat genetic and acquired disorders [125] due to their demonstrated high ability to condense and deliver nucleic acid molecules [126]. As mentioned in the previous section, the stabilization of the vectors composed of surfactant or lipid aggregates can be achieved by the addition of different additives such as cholesterol to increase the packing of phospholipid $[127,128]$, or polyethylene glycol (PEG) to protect nanoparticles from the immune system [129].

A large range of reports suggests the use of cationic surfactants as vectors for the delivery of nucleic acids $[126,130,131]$. Their success is related to easy synthetic pathways, as well as an efficient condensation and delivery of anionic nucleic acids through electrostatic interactions.

The cellular uptake of the nucleic acid-cationic surfactant complexes is driven by the disruption of the endosomal membrane due to the ion pair of the cationic surfactant and anionic lipids within the endosome membrane [132]. Regarding the structure, the complexes of the cationic surfactants and anionic phospholipids are usually arranged as inverted hexagonal phases, which are supposed to promote the release of the plasmid from the endosome into the cytoplasm [132].

Gemini are another class of very promising type surfactants that has been highly effective in delivering genetic material to cells. These systems show a very low critical micelle concentration, which allows a lower surfactant amount to achieve the same encapsulation capability [117].

Polymers and surfactants are able to encapsulate genes and drugs, as well as further cargo of interest for the treatment of different diseases or health problems, such as probiotics. Indeed, there have been considerable efforts in understanding the therapeutic effects of probiotic bacteria for different types of health issues, ranging from gastric diseases to atopic dermatitis [133]. Probiotics are living microorganisms with beneficial health effects to the host by replenishing natural gastrointestinal microbiota. The effectiveness of probiotics intake in some clinical cases has been already recognized e.g. in acute gastroenteritis [134]. About $10^{14}$ viable probiotic cells have been estimated to be potentially active against harmful bacteria in the gastrointestinal tract of an adult. Their balance depends on the diet of the host, medication intake, hygiene habits and diseased state [135]. Recent evidences highlight a remarkable role of the gut microbiota in the susceptibility to different disease phenotypes, which are often followed by dysbiosis, and are a major public health concern, e.g. obesity, diabetes and intestinal syndromes [136-138]. In this context, probiotics exhibited a pivotal influence in the modification of the gene expressions, which are involved in immunomodulation, nutrient absorption, suppression of pathogens, energy metabolism and intestinal barrier function such as stimulation of epithelial cell proliferation or induction of mucin secretion [133,139-141].

The positive health benefits provided by these probiotic agents are essentially strain- and disease-dependent. Moreover, designing a delivery vehicle, able to overcome the physiological variations (i.e. temperature, $\mathrm{pH}$, ionic strength, etc) with an efficient approach and without any harmful effect on tissues, is a challenging task. As previously discussed for the gene delivery, several (but rather similar) barriers can delay or prevent the delivery of probiotic bacteria in a safe and effective way. Probiotics are often administered orally and, in such case, the cells are primarily microencapsulated in order to protect them from the harsh conditions of the gastrointestinal passage, i.e. low $\mathrm{pH}$, presence of bile salts and enzymes. The microcapsules are usually formed by extrusion, emulsion, spray- and freeze-drying [142,143]. Polysaccharides (alginate, chitosan, gellan and xanthan gums) and milk proteins are among the most commonly used encapsulating agents [144]. From a formulation point of view, alginate-based materials have been the most explored, due to their biodegradability, very good cytocompatibility and mucoadhesive properties. Nevertheless, a new thread on systems for the encapsulation and delivery of probiotics is focused on their ability to provide for "smart" responses, according to the changes in the physiological environment [145]. For instance, it is possible to develop $\mathrm{pH}$ - or thermo-sensitive delivery systems, triggered by precise changes on physiological parameters [146]. As previously mentioned, sugar-based biopolymers have been in the spotlight, thanks to their biocompatibility and availability reasons [147]. The use of new tailor-made polymers with smart responses (e.g. using the aforementioned RDRP methods) reveals as a promising field to be explored in the 
near future and will allow the use of probiotics in the treatment of different health issues.

\section{Proteins and growth factor delivery}

Smart biomaterial approach is one of the fastest growing segments for the treatment of high impact diseases, such as cancers, dietary-related disorders, ischemic diseases and dramatic inflammatory responses. It is set to expand over the near future, fuelled mainly by the unmet requirements from the market for less invasive and more successful treatments, in particular in the key areas of inflammatory pathological conditions. The convenience and home use appeal for patients is the main driving factor of this industrial branch.

In this context, the most high impact cause of death and/or disability in developed countries refers to enzyme and protein disorders and related consequences [148,149]. Currently, affected patients cannot rely on a wide variety of surgical and medical options; this condition involves an urgent need of possible treatment alternatives, with a main challenge lying in the decrease of side effects and specific tailoring of the therapeutic approach. In detail, a promising strategy concerns the study of key pathological signalling mechanisms and related pathways involved in the switch control between normal and aberrant conditions. The rationale behind such an innovative perspective is on stage for the development of more effective chances to therapeutically tune the inflammatory pathways. An important target disorder where inflammatory processes are actively incorporated deals with cancers: therein, biosensing approaches, such as tuning and silencing of protein and enzymatic activity, as well as regulation of small molecule signalling are clever strategies with a huge potential for impact of people's daily life, towards the industrial nanobiotechnology sector growth. Over the years, nanotechnology has developed considerably as a result of novel technological discoveries, in the area of smart materials and related application. One area in bionanomaterials that offers great potential is represented by self-assembly approaches, thanks to their easy strategy for preparation and suitability for biotech engineering tailored modification. Self-assembly is the process of interand intra-molecular bonding through van der Waals forces, ionic interactions, H-bonding or hydrophobic interactions, which results in the formation of particularly formed structures, that can either form colloidal crystals or particle cluster among others. The intrinsic mobility of self-assembled complexes leads to ordered nanostructures upon equilibration between aggregated and non-aggregated states, thus providing a number of interesting properties such as error correction, self-healing, and high sensitivity to external stimuli. These structuring features are nowadays well understood and can be finely controlled in order to introduce and tune functional properties of self-assembled nanomaterials used for a wide range of applications.

Polymer-based self-assembled nanostructures, as well as organic nanomaterials (e. g. carbon nano-materials [150]) have great potential as drug delivery vehicles for invasive cancers, mainly as a result of their good biocompatibility [151] and natural degradation/resorption pathways [152]. On the other hand, self-assembled hydrogels, composed of biocompatible and amphiphilic polymer conjugates, have been shown to exhibit prolonged circulation in blood and preferential accumulation when administrated either in vitro or in vivo. From a targeted responsiveness point-of-view, cancers and aberrant conditions, demonstrated to be associated to low $\mathrm{pH}$ [153]. Thus, $\mathrm{pH}$ proved to be an excellent trigger for targeted cancer release carriers and further silencing of key pathological mechanisms therein involved. Another target involves small molecule changes in the cellular environment, such as Reactive Oxygen Species (ROS) [154] and formation of small amines/alcohol [155].

Besides, intercommunication between cells is mainly driven by growth factors, polypeptides which can modulate cellular behavior related to differentiation, proliferation and their ability to synthesize extra cellular matrix (ECM), by specifically targeting receptors on the cell surface [156]. Most biological processes are initiated by self-assembly reactions in the body. For example, assembly of amino acids to peptides to specific secondary, tertiary and quaternary structures that give rise to structural and functional proteins. From a material point-ofview, this naturally occurring phenomenon can be recapitulated artificially through spontaneous and random assembly of naturally occurring proteins or with a bottom-up approach by incorporating functional sequences, which dictate a specific biological response. In this context, hydrogel systems have been successfully employed for growth factor delivery and regenerative purposes, thanks to their ability to ensure a controlled cell migration $[157,158]$. Moreover, as previously discussed, hydrogels are widely applied for drug delivery purposes, as they mimic the natural ECM $[159,160]$ and allow a dual responsive drug release, offering the advantage of incorporation of further supramolecular structure, such as liposomes and further micro/nano carriers.

For instance, the peptide sequence (Pro-Lys-Gly)4(Pro-Hyp-Gly) 4(Asp-Hyp-Gly) 4 simulates the collagen self-assembly into a fibrous structure, which eventually triggers a hydrogel formation [161]. Similarly, $\alpha$ helical peptides [162], $\beta$ sheet peptides [163], $\beta$ hairpin peptides [164], amphiphilic peptides [165] and multi-domain peptides $[166,167]$ can lead to self-assembled hydrogels based on the chirality and nature of the aminoacidic side chains. As a result, the supramolecular hydrogels may vary in their physico-chemical properties such as stiffness, porosity and degradation properties.

The physico-chemical properties of hydrogel platforms play an important role in controlled delivery of bioactive factors or cells with a therapeutic potential. A recent study has shown the use of a three-dimensional, self-assembled type-I collagen microgel in modulating angiogenic responses of human mesenchymal stem cells [168]. Such ECM based microniches also help in promoting phenotypic changes by mimicking the signature matrix microenvironment of the predominant cell population in the tissue $[169,170]$. Design of self-assembling peptides using phage display with high affinity to growth factors have been utilized for spatio-temporal release of growth factors such as BMP-2 (YPVHPST) and TGF-B1 (LPLGNSH) for cartilage and bone regeneration [171]. Stimulus responsiveness property has also been incorporated in self-assembling hydrogels, where degradation is triggered in presence of an enzyme or reactive species as catalyst. The self-assembly of such multi-domain peptides allows greater control on fiber length and diameter, gelling and viscoelastic properties due to its modular design. $\mathrm{K}$ (SL)3RG(SL)3K-GRGDS is one example of a MMP2 cleavage specific peptide which undergoes the proteolytic degradation by collagenase IV [166]. For drug delivery, peptide amphiphiles loaded with therapeutic drugs self-assemble into fibrous nanostructures that disassembles and releases the drug upon enzymatic phosphorylation of the serine residue [172]. However, in vivo it becomes increasingly challenging to predict the local concentration of reactive enzymes. Hence, peptide self-assembling strategies incorporating ester groups, which hydrolyze in a more controlled manner than enzymatic reactions are favourable [173].

Self-assembled hydrogels made from functional extracellular matrix components have the advantage of achieving better biological recognition in a 3D tissue like environments with high fidelity. But the complexity, lack of control of the self-assembly process and variation from batch to batch may affect reproducibity. However, a semi synthetic approach in designing peptide sequences known to influence a biological function such as differentiation, maintenance of stemness or influence cellular secretome can be easily fabricated or coupled to a polymeric framework to match the physical properties of the tissue. This approach will endorse the need for designing a customised 3D hydrogel with tunable mechanical and biochemical features using functional recognition sequences. Another perspective, which has been thoroughly investigated, involves spherical microgels, an interesting bridging among macro-hydrogels and spherical microcarriers $[158,174]$. They can be defined as microscale hydrogels, offering a higher surface to volume ratio, compare to macroscale hydrogels. This unique feature enhances both microgels stability and their integration 
within the local tissue mass transport, by decreasing the bulk resistance $[175,176]$.

In a size and structural complexity decreasing progression, soft selfassembling frameworks for protein delivery can be encompassed by catanionic vesicles, colloidal hollow structures, based on pairing of oppositely charged ionic amphiphiles. In detail, the abovementioned amphiphiles easily self-aggregate [177] into multi-walled vesicular structures [178]. Vesicles are of increasing interest in the biotechnological field [179,180], mimicking biological membranes and their compartmentalization features [181]. Moreover, triggering factors for these structures involve salt/co-solutes addition, chain length and temperature, able to provide to multi-to-unilamellar transition and thus a controlled therapeutic release [182]. On the other side, liposomes offer another 'soft' alternative for tunable compartmentalization and biological responsive protein delivery.

Microspheres and hollow spheres are an additional tool for tailored delivery of proteins and growth factors, which have been extensively studied. Both synthetic (i.e. polyethyetylene glycol-PEG and polydimetylacrylamide-PDMA) and natural based polymers have been employed in their fabrication [183,184]. Different strategies for their production were proposed, such as emulsion, sacrifical template coating, chemical binding. Furthermore, ECM mimicking motifs allow the specific targeting of cellular proteins: this peculiar hallmark provides these reservoir systems with excellent performances and targeting properties, for growth factors delivery $[185,186]$.

Still keep on decreasing the available protein vehicle systems, there is considerable interest for carbon nano-onion [150]. These multi-shell fullerene structures pertain unique physicochemical properties of, such as ultra-small size, large surface to mass ratio, high flexibility and capability to be complexed (either covalently or non-covalently) with bioactive molecules, including small proteins like enzyme binding moieties [150] (Fig. 6).

\section{Synthetic therapeutics delivery}

\subsection{Challenges of small molecules in drug delivery}

Over the last twenty years, the main trend in pharmaceutical research was driven towards a growing interest in macromolecular therapeutics [187]. Nevertheless, most of the bioactive molecules still belongs to the class of small molecules under $500 \mathrm{Da}$. For instance, in cancer research, almost $75 \%$ of these therapeutics derive from synthetic sources [188]. The major issue of small molecule therapeutics is represented by the toxic side effects of high doses, due to an overall poor biodistribution and rapid clearance [189]. Moreover, when a low invasive and high patient friendly administration route is chosen, such as the oral approach, additional factors can influence and reduce the therapeutic efficacy of the majority of Active Pharmaceutical Ingredients (APIs) with poor solubility and low permeability in gastrointestinal environment [190]. Besides solubility issues of hydrophobic compunds, a larger group of drugs are susceptible to several biochemical barriers, such as enzymatic attack, hydrolysis, degradation in the low gastric $\mathrm{pH}$, unspecific endocytosis of the extended mucosa surface [191], pre-systemic metabolic pathways [192], intracellular biotrasformations [193] and plasma proteins complexation and recognition by the cells of the mononuclear phagocyte system [194].

Nowadays, the low bioavailability still represents a concrete issue: $>90 \%$ of active compounds discovered and approved since 1995 belong either to class II or IV in the standard of Biopharmaceutical Classification System (BCS) [195]. Several strategies were developed to enhance both solubility and permeability of APIs. These approaches include the modification of both physical and chemical properties of the API [196]. The modification of physical characteristics is mainly focused on micronization techniques $[197,198]$ reduction of crystal sizes, amorphization and stabilization of such solid dispersions [199,200]. Recently, further efforts have been focused on the development of specific organs and tissues targeting, while improving drug permeability on specific diseased cell targets.

\subsection{Lipid based-nanovesicles}

As previously mentioned, lipid based nanovesicles (LNVs) are defined as spherical vesicles constituted by a bilayered lipid membrane. In a size-driven perspective, these colloidal carriers can be divided into small unilamellar vesicles (SUVs, with diameter $<200 \mathrm{~nm}$ and single bilayer membrane), large unilamellar vesicles (LUVs, diameter ranging 200-1000 nm, single bilayer membrane), giant unilamellar vesicles (GUVs, diameter $>1000 \mathrm{~nm}$, single bilayer membrane), multilamellar vesicles (MLVs composed by concentric vesicles, or multiple concentric bilayers) and multi vesicular vesicles (MVVs, composed by multiple vesicles confined inside a larger one). Fig. 7 groups the different types of nanovesicular systems, with increasing size characteristics. Since the first LNV proposed by Gregoriadis in 1974 [122], a large number of nanovesicicular systems were developed. Such an impressive success is due to their ability to incorporate functional biomacromolecules on the lipid bilayer, proposing as smart, flexible, stimuli responsive systems. Key features of these colloidal carriers involve the API encapsulation efficiency (EE), the particle size distribution and the $\mathrm{z}$ potential.

Over lipidic nanovesicles class, liposomes were the first discovered structures, composed by natural phospholipids membranes in the form

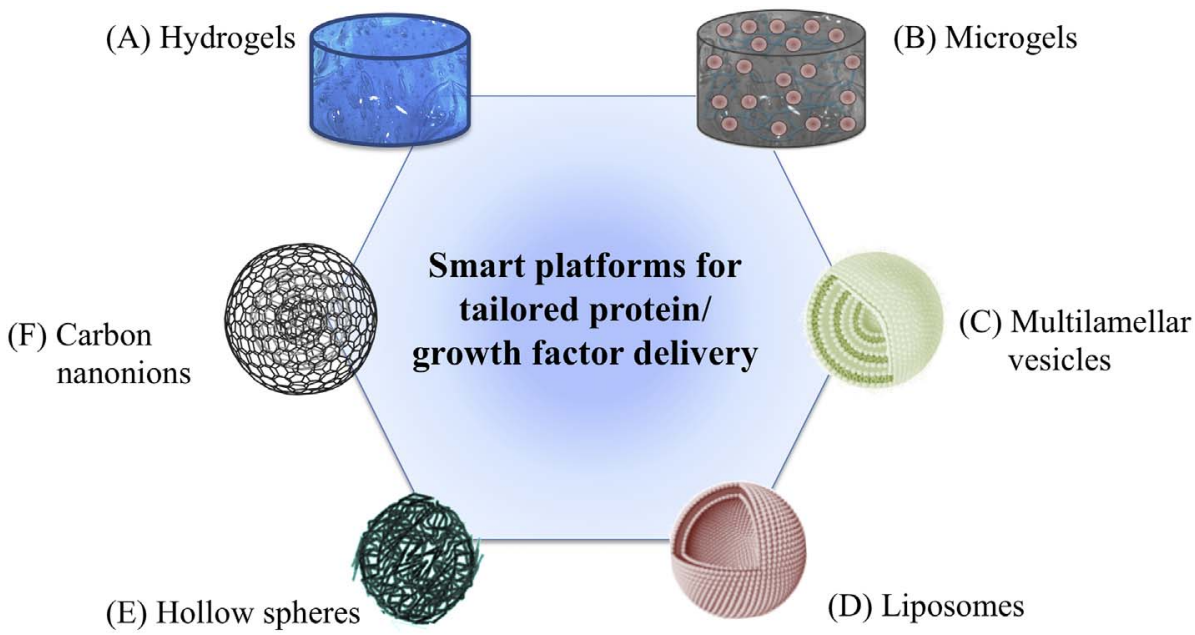

Fig. 6. Schematic representation recapitulating platforms for protein/growth factor delivery. Scaffold size is decreasing clockwise: (A) hydrogels, characterized by macrocrosslinks, (B) microgels, composed by the interconnection of microparticles, (C) multilamellar vesicles, colloidal hollow structures ranging in the micron size, (D) liposomes, soft lipidic-based nanocontainers, (E) hollow spheres, with tunable size, from $100 \mathrm{~nm}$ to the micro-range and (F) carbon nanonions, carbon based structures, spanning within the $10 \mathrm{~nm}$ average diameter. 

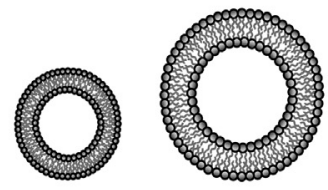

SUV $<200 \mathrm{~nm}$

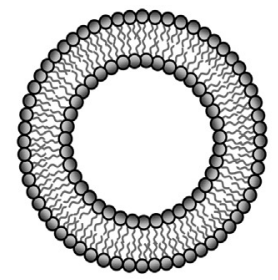

GUV

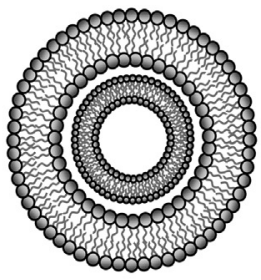

MLV

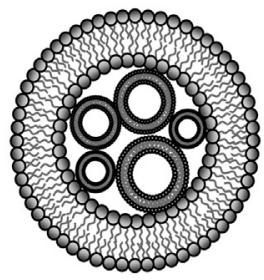

MVV
Fig. 7. Schematic representation of the main lipid based nanovesicular systems. According to their size and lamellar levels, vesicles can be classified as (left to right): SUV (Small Unilamellar Vesicles), LUV (Large Unilamellar Vesicles), GUV (Giant Unilamellar Vesicles), MLV (Multi-Lamellar Vesicles) and MVV (Multi Vesicular Vesicles). of SUV and MLV. Nowadays, further in-depth researches explored the use of many synthetic phospholipids like phosphatidylglycerol, phosphatidylethanolamine, phosphatidylcholine and phosphatidylserine [201]. The first method developed for the encapsulation of hydrophilic compounds refers to the thin layer hydration (TLH), characterized by a very low EE due to the highly non-favored partition of hydrophilic molecules inside the vesicle cavity versus the surrounding aqueous medium. Further methods involved the combination of TLH with other approaches to enhance the EE of hydrophilic molecules: reiterated freeze-thaw (FT), reverse phase evaporation (REV) and dehydration-rehydration of empty vesicles (DRV).

The FT method allows the spontaneous MLVs disruption by the water ice crystals produced in the freezing process, leading to the fabrication of SUVs. The EE can be modulated by tuning the FT cycle rate, the aqueous solute and lipid concentrations. Additional extrusion steps after FT have shown to improve the size distribution, such as the encapsulation of the hydrophilic drug itopride in liposomes [202]. On the other hand, multiple FT cycles can increase liposome diameter and polydispersity, when liposome components are highly susceptible to salt concentration (i.e. egg phosphatidylcholine) [203].

Reverse phase evaporation method (REV) is another approach to encapsulate small hydrophilic drugs. Therein, the lipids are dissolved in an organic phase and further incorporated in an aqueous phase with the drug. The obtained emulsion is subsequently treated with evaporationhydration cycles, leading to the formation of liposomes, mainly LUVs with large EE. For example, the addition of the REV step to TLH introduced an EE increase in the case of sumatriptan succinate [204]. Conversely the utilization of REV can result in a decrease of hydrophobic drugs encapsulation efficiency, compared to TFH, as in the case of acetazolamide, inside multilamellar vesicles [205] and ketoprofenhydroxypropyl- $\beta$-cyclodextrin complexes included into large unilamellar vesicles [206]. Liposomal vesicles can be fabricated by means of a dehydration-rehydration method (DRV), adding a buffer to the thin film and further lyophilize. The solid pellet is then rehydrated with the drug solution. Compared to conventional TFH, DRV produced a high drug/lipid ratio in the case of vancomycin [207], with an impressive increase of EE (30 and 130 fold), for both non-decorated and pegylated liposomes, respectively. Recent reviews discussed innovative methods for liposomes fabrication [208-210], including microfluidics [211,212], compressed/supercritical fluids for the incorporation of both hydrophilic and lipophilic drugs into the vesicles [213,214].

A large variety of liposomal formulations was developed by incorporating one or more multitasking ligands within the vesicle membrane. Liposomes can exert a passive targeting by enhancing the permeability retention time [215] or by depletion of macrophages, as shown in the case of the hydrophobic drug amphotericin B [216]. On the other hand, active targeting features can involve the binding mechanisms of liposomes towards bioactive receptors, such as antibody conjugates [217] or permeation enhancers, like cell-penetrating peptides (CPPs) [218]. Stimuli-responsiveness is an attractive perspective for specifically triggered drug release towards liposomes, aiming to reduce the side effects of unspecific targeting through a dual action.
Within such an approach, the therapeutic cargo can be released in the cytoplasm by targeting the lower $\mathrm{pH}$ inside the endosome, while providing for conformational changes of dioleylphosphoethanolamine (DOPE) and cholesterylhemisuccinate [219]. At present, doxorubicin is one of the most studied drugs for liposomal triggered-release, with a thermosensitive formulaton, ThermoDox ${ }^{\circledR}$, in clinical trials. Other liposomal formulations with small bioactive molecules are available in the market, with good encapsulation efficiency. Nevertheless targeted formulations or stimuli-responsive liposomes are still challenging at a research stage.

The main reason for such a limited transfer of liposomal formulation into the biopharmaceutical market relies on the drawback of their low physico-chemical stability, due to the intrinsic poor aqueous solubility of phospholipids, which tend to aggregate into bigger clusters [220]. As a consequence, liposome suspensions are usually lyophilized and stored as dry products [221].

\subsection{Non-liposomal nanovesicles}

The limited efficacy of liposomes broadens research horizons towards employing lipids in combination with alternative self-assembling materials, such as surfactants [222,223], polymers [224] and peptides [225].

Non-liposomal nanovesicles can be classified according to the alternative component versus phospholipid: niosomes, sphingosomes, pharmacosomes and quatsomes.

Niosomes are prepared by hydrating a mixture of lipids with nonionic surfactants, such as alkyl ethers, alkylesters alkylamides, fatty acids and amino acids. Niosomes are able to encapsulate both hydrophilic and hydrophobic drugs. The use of cholesterol as lipid component leads to more rigid and less leaky bilayers, which makes it particularly suitable for small drugs such as calcein [226] or poorly soluble beclomethasone dipropionate [223]. Niosomes exhibit an overall short-term stability, which strongly depends on the additional membrane components [227].

Sphingosomes are composed by natural or synthetic sphingolipids, which form nanovesicles in the form of SUVs and LUVs. Compared to niosomes, they show an enhanced stability, as well as an improved resistance against hydrolysis, compared to liposomes. A promising application of sphingosomes was found in the encapsulation of alchaloids like vinorelbine [228].

Normal phospholipids are replaced by lipids covalently bonded to the API to be delivered, leading to create pharmacosomes. Those structures demonstrated higher encapsulation efficiency than liposomes [229].

Quatsomes are unilamellar nanovesicles composed by quaternary ammonium surfactants and sterols (e. g. cholesterol and $\beta$-sitosterol) [230]. Several surfactants were utilized so far: cetrimonium bromide (CTAB), myristalkonium chloride (MKC) and cetylpyridinium chloride (CPC). Their unilamellar and homogeneous morphology proposes these nanovesicles as excellent candidates for stable functionalization aimed to passive targeting [214]. Their key features consist of their very low 
size, good dispersion, as well as the remarkable and long-term stability [231].

Conventional fabrication methods like TFH were combined with size reducing post formation steps. Extensively studied examples are ultrasound sonication, proposed for liposomal encapsulation of anticancer drugs [232], extrusion reduced polydispersity and size of niosomes loaded with tretinoin [233] or high-pressure homogenization with a uniform dispersion of SUVs containing the poorly soluble drug fenofibrate [234]. The most novel technologies are based on compressed fluids (CFs) [214,235], microfluidics [211,232] and freezedrying of emulsions [236]. In compressed fluid technology (CFs), the gas is rapidly pressurized, which modulates the solvent density and solubilization power. Fast density variations are more significant by crossing the critical point towards a phase transition. The broadest fluid employed in this field is carbon dioxide $\left(\mathrm{CO}_{2}\right)$ thanks to its mild critical conditions $\left(\mathrm{P}_{\mathrm{c}}=74 \mathrm{bar}, \mathrm{T}_{\mathrm{c}}=30.95{ }^{\circ} \mathrm{C}\right)$, which allow the application to thermosensitive compounds. Within this group, it is worth to mention the Depressurization of Expanded Liquid Organic Solution-SUSPension (DELOS SUSP) [214,231] and DESAM (Depressurization of an Expanded Solution into Aqueous Media) [237].

Another unconventional method for nanovesicles production is based on the freeze-drying of emulsions. Herein, the hydrophilic (i. e. drug and/or cryoprotectant) and hydrophobic components (i. e. drugs and lipids) are dissolved in water and organic phase respectively, leading to an emulsion. The mentioned emulsion is freeze-dried and the solid pellet is resuspended, prior to its use. Several small molecule drugs, including hydrophobic (e. g. flurbiprofen), hydrophilic (e. g. paeoniflorin) and amphiphilic (e. g. barberin) APIs, were encorporated into liposomal SUVs [236].

The new generation of nanovesicles shows complementary features compared to liposomes, overcoming most of their drawbacks in terms of formulation stabililty, easy technology and cost-effectiveness. Besides liposomes have already shown a complete potential as nanocarriers, non-liposomal L-NVs propose as promising frontiers, from the lab bench to clinical practice.

\section{Nanocarriers for bioimaging and diagnostic}

High-resolution cellular and tissue imaging is a highly interdisciplinary field, merging expertise in materials chemistry, nanotechnology, biology, physics and medicine. In this context, optical and fluorescent imaging is a research branch of increasing interest because is non-invasive, involves the use of visible, ultraviolet and infrared light decreasing the exposure to harmful radiation, and can produce images of organs, soft tissue and cells both in vitro and in vivo.

Applications of fluorescent carriers span from in vitro biologically relevant processes associated with diseases and aberrant situation (i.e. cancers) to in vivo imaging of biological pathways. Thus, the main characteristics for a colloidal platform involve highly tunable size and surface, ability to further target the cell surface with enzyme-binding motifs penetration and imaging capabilities. Over the past years, fluorescent carriers have been developed for both localization of specialized nanoparticles in the cells and diagnostic applications. This elegant approach allowed nanoparticles cellular uptake and their compartmentalization in specific tissues, with multi-tasking features. Indeed, fluorescent delivery systems represent a non-invasive technique to study live events at a molecular level, as well as diagnostic tool, which can identify abnormalities on patients, before or after the development of the disease.

One of the main strategies to enhance bio-imaging rely on the development of imaging probes for the biologically relevant near infrared (NIR) and far-red region, where tissue exhibit minimal absorbance [238]. Therefore, the development of new organic dies molecule emitting in the far-red and NIR region demonstrated increasing interest over the scientific community [239]. These molecules are able to reduce the tissue auto-fluorescence and allow a high resolution imaging with deeper tissue penetration.

In this context, Carbon Nano Materials (CNMs) have been proposed for biomedical application, due to their low toxicity, small size, and large surface area. Surface functionalization on these materials is possible and well explored, usually through chemical reaction directly with the $\mathrm{sp}^{2}$ carbon atoms present on the material surface. This allows their surface modification to make CNMs soluble in aqueous environments and biocompatible, besides readily internalized by cells. On the other hand this chemically controlled surface functionalization both by covalent and noncovalent approach (e.g $\pi-\pi$ stacking), allowed chemist to create specialized nanoparticle specific for bioimaging. Moreover, some CNMs such as single walled carbon nanotubes (SWCNTs) [240], carbon dots (CDs) [241] and graphene, can also act as imaging agents themselves, due to their intrinsic optical properties [242].

Multi-shell fullerenes, known as carbon nano-onions (CNOs), have recently gathered great interest among researchers and have been successfully applied in a variety of different fields of application such as energy storage [243,244], catalysis [245], supercapacitors [246] and imaging [247].

CNOs are attractive platforms for imaging, diagnostic and therapeutic applications, thanks to their small size. Moreover, their surface can be chemically modified modulating cell penetration and cell recognition respectively [150]. Recent reports showed that fluorescently labelled CNOs, with an average of $5 \mathrm{~nm}$, exhibit weak inflammatory potential and a low cytotoxicity [248]. They are readily internalized by cancer cells and deposited in the lysosomes [249,250]. Toxicological studies were conducted on fluorescein-functionalized CNOs both in vitro and in vivo. A comparison among the abovementioned functionalized CNOs and functionalized carbon nanotubes (CNTs) in terms of cytotoxicity and immunomodulatory properties demonstrated that CNOs exhibit efficient cellular uptake and reveal a bright fluorescence signal [248]. These biologically relevant features proposed CNOs at the forefront for biomedical applications. Moreover, in vivo studies on zebrafish (Danio rerio) in the development stage, confirmed their ecocompatibility and homogenous distribution in a vertebrate model system, exhibiting excellent performances as biomedical probes [251]. An example of multi-functionalized CNOs (f-CNOs) as targeted delivery system have been reported, where CNOs were surface functionalized with fluorescein and folic acid moieties for both imaging and targeting of cancer cells [250]. The f-CNOs showed a bright fluorescence and a selective and rapid internalization in cancer cells (HeLa and $\mathrm{KB}$ cells) without toxicity. The f-CNOs were localized into specific cell compartments using a correlative approach with confocal and transmission electron microscopy [250] (Fig. 8).

Fullerene $\mathrm{C}_{60}$ is a symmetrical sphere made of carbon atoms with a diameter of $1 \mathrm{~nm}$, which has been widely used for biomedical application. Nevertheless the increasing interest on other CNMs such as CNTs and graphene, several examples of fullerene used for drug delivery and bio-imaging are present in literature. For examples, biocompatible color-tunable photoluminescent fullerene nanomaterials were synthetized by conjugating $\mathrm{C}_{60}$ particles with tetraethylene glycol (TEG) molecules [252]. Their high quantum yield and water solubility make them suitable for bio-imaging application. Recently a biocompatible and water-soluble mesoporous silica nanoparticle (MSN) coated with fullerene molecules was reported for the drug release of doxorubicin (DOX) in a mild acidic environment [253]. Furthermore, C60-modified MSN showed a green fluorescence of peculiar interest for cellular imaging.

Several carbon nanomaterials are known to emit fluorescence light upon photo-excitation [242]. The leading examples on CNMs with intrinsic optical properties are semiconducting SWCNTs, which show a structure dependent fluorescence in the biologically important 1300-1400 nm near-infrared window (NIR-IIa window).

The live imaging of mouse cerebral vasculature using SWCNTs was previously achieved without craniotomy, cranial windows and skull thinning techniques, which are usually required [254]. The reduced 
(A)
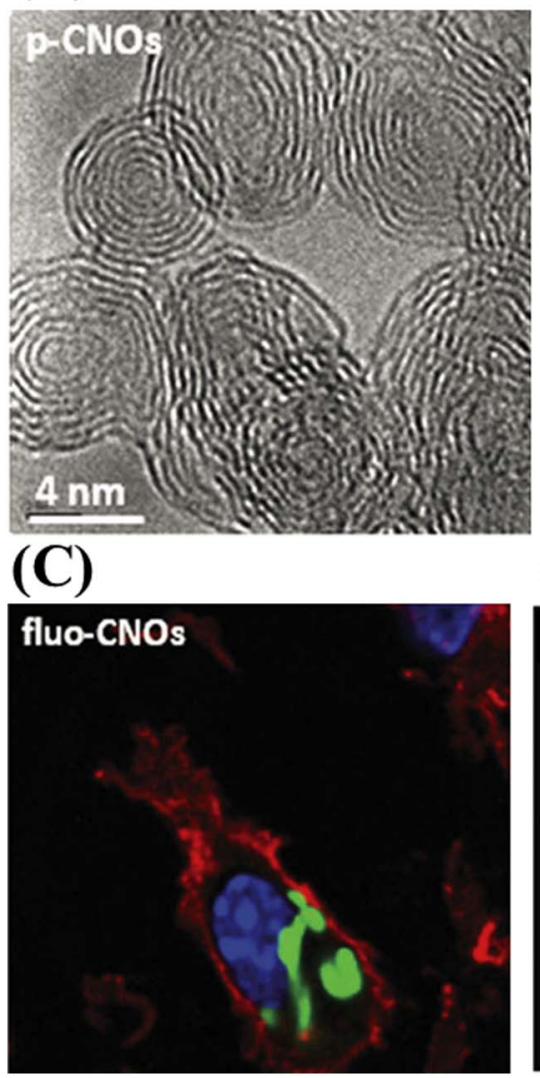

(B)

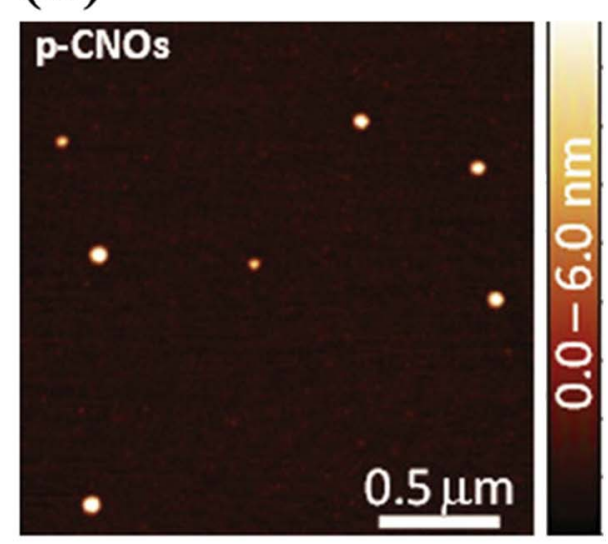

(D)

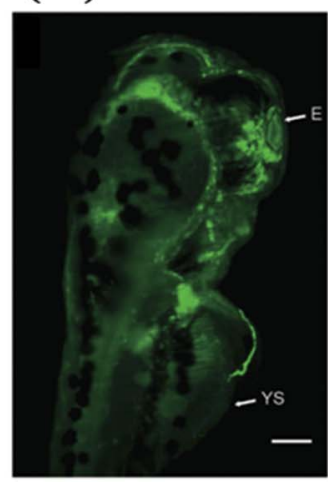

Fig. 8. High resolution TEM image (A) and AFM topograph (B) of pristine CNOs. Confocal microscopy of C57BL $/ 6$ BMDCs incubated in the presence of fluorescein-CNOs (green), stained with wheat germ agglutinin-Alexa Fluor594 (red) and nuclei stain Hoescht (blue) (C). (A), (B) and (C) are reproduced from [248], Copyright 2013 WileyVCH Verlag GmbH \& Co. KGaA. Reproduced with permission. (D) Representative optical images of zebrafish exposed to BODIPY-CNOs (green). Maximum intensity projections of the superior part (left) and tail (right) (Scale bars, $100 \mu \mathrm{m}$ ). (For interpretation of the references to color in this figure legend, the reader is referred to the web version of this article.)

Reprinted with permission from [251]. Copyright 2016 Nature Publishing Group. short-wavelength photon scattering in the NIR-IIa window, allowed an improved imaging resolution to a depth of $>2 \mathrm{~mm}$ using three-dimensional in vivo imaging through confocal or two-photon techniques. Carbon nanotubes offer also a promising tool as drug delivery system, due to their spectroscopic properties and easy surface functionalization. Targeted drug delivery system have been reported with CNTs where a drug is loaded on their surface, either covalently or by adsorption, together with a ligand to facilitate the targeting of selective cancer cells. An example is the loading of DOX on SWCNTs through $\pi-\pi$ stacking which is feasible due to the aromatic moiety of the drug $[255,256]$. The DOX was loaded on a high ratio on the SWCNTs surface, and the drug was readily released within the acidic tumor microenvironment. Similarly to the adsorption of an aromatic drug molecule, an aromatic organic dye molecule can be absorbed on the surface of CNMs. For instance boron dipyrromethene (BODIPY)-pyrene/CNTs [257] and pyrene-BODIPY/CNOs [258] hybrids have been reported as imaging probes, where pyrene is used as an anchoring group.

Similarly to SWCNTs, CDs are biocompatible carbon-based nanoparticles with intrinsic fluorescence, bypassing possible issues related to multiple functionalization steps with small organic fluorophore molecules. Moreover, their surface can be chemically modified allowing their functionalization with a therapeutic agent and a specific ligand to apply them as a targeted drug delivery system. With a diameter below $10 \mathrm{~nm}$ and their low toxicity, they are widely used for biomedical applications. Favourable characteristic of CDs are their size- and excitation wavelength- dependent photoluminescence (PL) behavior, high stability and resistance to photo bleaching. Biocompatibility studies and bio distribution of CDs have been explored on zebrafish as a vertebrate model, proving their compatibility with life and validating their application as multi-color imaging probe [259].

CDs have a tunable emission wavelength, depending on the excitation wavelength, and their reported fluorescence wide-ranged from NIR [260], to visible [241], to deep ultraviolet [261]. Their versatile optical properties allowed them to be employed in several biomedical applications, from in vivo imaging to drug delivery.

Further carbon-based structures, fullerene [262] and CNTs [263], have been proposed for the development of new MRI contrast agents. In detail, fullerenes can encapsulate gadolinium, decreasing its toxicity. An example is represented by gadolinium (Gd)-containing $\mathrm{C}_{80}$ endohedrals (Trimetaspheres ${ }^{\mathrm{TM}}$, TMS, Gd3N@C80), which were used as Atherosclerotic Targeting Contrast Agents (ATCA) for cardiovascular magnetic resonance (CMR) [264]. Furthermore, gadolinium-functionalized MWCNTs were recently studied as contrast agents for MRI cell labelling and tracking [263].

Multi-modal molecular imaging approach has been proposed, by a synergistic combination of two or more detection techniques [265]. Examples of the "dual active" method include the development of nanoparticles combining fluorescence and magnetic resonance imaging: they merge effectively the high sensitivity of the fluorescence phenomenon with the high spatial resolution of MRI.

CNMs are quite promising for biomedical applications, as imaging tools, due to their small size, biocompatibility and optical characteristics. Besides their intrinsic optical properties and resistance to photo bleaching, their quantum yield is lower than small organic molecule. However, a merged strategy with synthetic dyes and CNMs hybrids can lead to extremely powerful imaging probe for both in vitro and in vivo applications.

\section{Conclusions and future outlooks}

Self-assembly mechanisms mimick biological processes by recapitulating morphological structure and organization of native tissues. 
Overall, all strategies discussed herein, explain the use of different colloidal systems to be employed for a tailored bioactive molecule depot. These strategies depend on the hierarchical and functional complex stuctures involved, including the target living tissues. The functional design of the constructs is encoded by the properties of the fundamental units. The tunable characteristics of the systems generated therefore, can ensure precise release of bioactive factors or induce a conformational change at the tissue interface. Thus, controlled fabrication and selection of colloidal-based scaffolds can help in rapid development of cost-effective engineered solutions for clinical use.

\section{Acknowledgements}

Istituto Italiano di Tecnologia (IIT) is greatly acknowledged for funding. S.G. acknowledges the COST Action CA 15107 "MultiFunctional Nano-Carbon Composite Materials Network (MultiComp)". B.M. acknowledges funding from the People Program (Marie Curie Actions) of the European Union's Seventh Framework Program FP7/ 2007-2013/under REA grant agreement no. 606713 BIBAFOODS. The Portuguese Foundation for Science and Technology (FCT) is acknowledged through the project PTDC/AGR-TEC/4814/2014 and researcher grant IF/01005/2014. A. C. F. acknowledges "Fundação para a Ciência e Tecnologia", Grant: SFRH/BPD/99982/2014. P. M. acknowledges the Danish National Research Foundation (DNRF 122) and the Villum Foundation (grant no. 9301). This work has been in part supported by the Italian Ministry of Instruction, University and Research (MIUR), PRIN 2010-11, [20109PLMH2], by the "Fondazione Beneficentia Stiftung" Vaduz, by Fondo di Ateneo FRA 2015 and FRA 2016.

\section{References}

[1] Patel NR, Pattni BS, Abouzeid AH, Torchilin VP. Nanopreparations to overcome multidrug resistance in cancer. Adv Drug Deliv Rev 2013;65(13):1748-62.

[2] Wong BS, Yoong SL, Jagusiak A, Panczyk T, Ho HK, Ang WH, et al. Carbon nanotubes for delivery of small molecule drugs. Adv Drug Deliv Rev 2013;65(15):1964-2015.

[3] Couvreur P, Vauthier C. Nanotechnology: intelligent design to treat complex disease. Pharm Res 2006;23(7):1417-50.

[4] Lapasin R, Pricl S. Rheology of Industrial Polysaccharides: Theory and Applications. London: Blackie Academic \& Professional; 1995.

[5] Lin C-C, Metters AT. Hydrogels in controlled release formulations: network design and mathematical modeling. Adv Drug Deliv Rev 2006;58:1379-408.

[6] Ahmed EM. Hydrogel: preparation, characterization, and applications: a review. J Adv Res 2015;6:105-21.

[7] Grassi M, Lapasin R, Pricl S. Modeling of drug release from a swellable matrix. Chem Eng Commun 1998;169:79-109.

[8] Milcovich G, Antunes F, Golob S, Farra R, Grassi M, Voinovich D, et al. Thermoresponsive hydrogels from cellulose-based polyelectrolytes and catanionic vesicles for biomedical application. J Biomed Mater Res A 2016;104(7):1668-79.

[9] Mao B, Divoux T, Snabre P. Normal force controlled rheology applied to agar gelation. J Rheol 2016:60:473-89.

[10] Pettolino FA, Walsh C, Fincher GB, Bacic A. Determining the polysaccharide composition of plant cell walls. Nat Protoc 2012;7:1590-607.

[11] Gershlak JR, Hernandez S, Fontana G, Perreault LR, Hansen KJ, Larson SA, et al. Crossing kingdoms: using decellularized plants as perfusable tissue engineering scaffolds. Biomaterials 2017;125:13-22.

[12] Posocco B, Dreussi E, de Santa J, Toffoli G, Abrami M, Musiani F, et al. Polysaccharides for the delivery of antitumor drugs. Materials 2015;8:2569-615.

[13] Matricardi P, Alhaique F, Coviello T, editors. Introduction in Polysaccharide Hydrogels: Characterization and Biomedical Applications. Singapore: Pan Standford Publishing; 2015 (Chapter 1).

[14] Matricardi M, Di Meo C, Coviello C, Hennink WE, Alhaique F. Interpenetrating polymer networks polysaccharide hydrogels for drug delivery and tissue engineering. Adv Drug Deliv Rev 2013;65:1172-87.

[15] Borgogna M, Marsich E, Donati I, Paoletti S, Travan A. Matricardi P, Alhaique F, Coviello T, editors. Polysaccharide hydrogels: Characterization and biomedical applications. Singapore: Pan Standford Publishing; 2015 (Chapter 2).

[16] Zhao QS, Ji QX, Xing K, Li XY, Liu CS, Chen X. Preparation and characterization of novel porous hydrogel films based on chitosan and glycerolphosphate. Carbohydr Polym 2009;76:410-6.

[17] Chaudhuri O, Gu L, Klumpers D, Darnell M, Bencherif SA, Weaver JC, et al Hydrogels with tunable stress relaxation regulate stem cell fate and activity. Nat Mater 2015:1-9. NMAT4489.

[18] Leoni L, Desai TA, Burke JE. Micromachined biocapsules for cell-based sensing and delivery. Adv Drug Deliv Rev 2004;56:211-29.

[19] Grassi M, Grassi G. Application of mathematical modelling in sustained release delivery systems. Expert Opin Drug Deliv 2014;11:1299-321.

[20] Peppas NA, Huang Y, Torres-Lugo M, Ward JH, Zhang J. Physicochemical foundations and structural design of hydrogels in medicine and biology. Annu Rev Biomed Eng 2000;2:9-29.

[21] Miller-Chou AA, Koening JK. A review of polymer dissolution. Prog Polym Sci 2003;28:1223-70.

[22] Prudic A, Ji Y, Luebbert C, Sadowski G. Influence of humidity on the phase behavior of API/polymer formulations. Eur J Pharm Biopharm 2015;94:352-62.

[23] Singh M, Lumpkin J, Rosenblat J. Mathematical modeling of drug release from hydrogel matrices via a diffusion coupled with desorption mechanism. J Control Release 1994;32:17-25.

[24] Singh MP, Stefko J, Lumpkin JA, Rosenblatt J. The effect of electrostatic charge interactions on release rates of gentamicin from collagen matrices. Pharm Res $1995 ; 12: 1205-10$

[25] Huang J, Wigent RJ, Schwartz JB. Drug-polymer interaction and its significance on the physical stability of nifedipine amorphous dispersion in microparticles of an ammonio methacrylate copolymer and ethylcellulose binary blend. J Pharm Sci 2008;97:251-62.

[26] Paulsson M, Edsman K. Controlled drug release from gels using lipophilic interactions of charged substances with surfactants and polymers. J Colloid Interface Sci 2002:248:194-200.

[27] Byrne ME, Park K, Peppas NA. Molecular imprinting within hydrogels. Adv Drug Deliv Rev 2002;54:149-61.

[28] Farra R, Dapas B, Pozzato G, Scaggiante B, Agostini F, Zennaro C, et al. Effects of E2F1-cyclin E1-E2 circuit down regulation in hepatocellular carcinoma cells. Dig Liver Dis 2011;43:1006-14.

[29] Gao K, Huang L. Achieving efficient RNAi therapy: progress and challenges. Acta Pharm Sin B 2013;3:225--231.

[30] Putnam D. Polymers for gene delivery across length scales. Nat Mater 2006;5:439-51.

[31] Phua K, Leong KW. Microscale oral delivery devices incorporating nanoparticles. Nanomedicine (London) 2010;5:161-3.

[32] Knipe JM, Strong LE, Peppas NA. Enzyme- and pH-responsive microencapsulated nanogels for oral delivery of siRNA to induce TNF- $\alpha$ knockdown in the intestine. Biomacromolecules 2016;17:788-97.

[33] D'Apolito R, Tomaiuolo G, Taraballi F, Minardi S, Dickson Kirui D, Liu X, et al. Rec blood cells affect the margination of microparticles in synthetic microcapillaries and intravital microcirculation as a function of their size and shape. J Control Release 2015;217:263-72.

[34] Scaggiante B, Dapas B, Farra R, Grassi M, Pozzato G, Giansante C, et al. Improving siRNA bio-distribution and minimizing side effects. Curr Drug Metab 2011;12:11-23.

[35] Agostini F, Dapas B, Farra R, Grassi M, Racchi G, Klingel K, et al. Potential applications of small interfering RNAs in the cardiovascular field. Drugs Future 2006;3:513-25.

[36] Farra R, Grassi M, Grassi G, Dapas B. Therapeutic potential of small interfering RNAs/micro interfering RNA in hepatocellular carcinoma. World J Gastroenterol 2015;21:8994-9001.

[37] Farra R, Dapas B, Baiz D, Tonon F, Chiaretti S, Del SG, et al. Impairment of the Pin1/E2F1 axis in the anti-proliferative effect of bortezomib in hepatocellular carcinoma cells. Biochimie 2015;112:85-95.

[38] Farra R, Dapas B, Pozzato G, Giansante C, Heidenreich O, Uxa L, et al. Serum response factor depletion affects the proliferation of the hepatocellular carcinoma cells HepG2 and JHH6. Biochimie 2010;92:455-63.

[39] Huang Y, Hong J, Zheng S, Ding Y, Guo S, Zhang H, et al. Elimination pathways of systemically delivered siRNA. Mol Ther 2011;19:381-5.

[40] Jackson AL, Linsley PS. Recognizing and avoiding siRNA off-target effects for target identification and therapeutic application. Nat Rev Drug Discov 2010;9:57-67.

[41] Kaneda Y. Gene therapy: a battle against biological barriers. Curr Mol Med 2001;1:493-9.

[42] Juliano RL. The delivery of therapeutic oligonucleotides. Nucleic Acids Res 2016;44(14):6518-48.

[43] Barba AA, Lamberti G, Sardo C, Dapas B, Abrami M, Grassi M, et al. Novel lipid and polymeric materials as delivery systems for nucleic acid based drugs. Curr Drug Metab 2015;16:427-52.

[44] Leonetti JP, Degols G, Lebleu B. Biological activity of oligonucleotide-poly(L-ly sine) conjugates: mechanism of cell uptake. Bioconjug Chem 1990;1:149-53.

[45] Liang HF, Yang TF, Huang CT, Chen MC, Sung HW. Preparation of nanoparticles composed of poly(gamma-glutamic acid)-poly(lactide) block copolymers and evaluation of their uptake by HepG2 cells. J Control Release 2005;105:213-25.

[46] Grassi G, Scaggiante B, Dapas B, Farra R, Tonon F, Lamberti G, et al. Therapeutic potential of nucleic acid-based drugs in coronary hyper- proliferative vascular diseases. Curr Med Chem 2013;20:3515-38.

[47] Colombo P. Chimera agglomerates for extravascular delivery of particulate drugs. 17th International Symposium on Microencapsulation Nagoya, Japan September 29th - October 1st 2009.

[48] Kumar V, Palazzolo S, Bayda S, Corona G, Toffoli G, Rizzolio F. DNA nanotechnology for cancer therapy. Theranostics 2016;6:710-25.

[49] Kumar V, Bayda S, Hadla M, Caligiuri I, Russo SC, Palazzolo S, et al. Enhanced chemotherapeutic behavior of open-caged DNA@Doxorubicin nanostructures for cancer cells. J Cell Physiol 2016;231:106-10.

[50] Toffoli G, Hadla M, Corona G, Caligiuri I, Palazzolo S, Semeraro S, et al. Exosomal doxorubicin reduces the cardiac toxicity of doxorubicin. Nanomedicine 2015;10(19):2963-71.

[51] Kumar V, Toffoli G, Rizzolio F. Fluorescent carbon nanoparticles in medicine for cancer therapy. ACS Med Chem Lett 2013;4:1012-3.

[52] Sponchia G, Ambrosi E, Rizzolio F, Hadla M, Del Tedesco A, Russo Spena C, et al. 
Biocompatible tailored zirconia mesoporous nanoparticles with high surface area for theranostic applications. J Mater Chem B 2015;3:7300-6.

[53] Xue HY, Guo P, Wen WC, Wong HL. Lipid-based Nanocarriers for RNA delivery. Curr Pharm Des 2015;21:3140-7.

[54] Bochicchio S, Dalmoro A, Barba AA, Grassi G, Lamberti G. Liposomes as siRNA delivery vectors. Curr Drug Metab 2017;18:882-92.

[55] Muller LK, Landfester K. Natural liposomes and synthetic polymeric structures for biomedical applications. Biochem Biophys Res Commun 2015;468:411-8.

[56] Bozzuto G, Molinari A. Liposomes as nanomedical devices. Int J Nanomedicine 2015;10:975-99.

[57] Junquera E, Aicart E. Recent progress in gene therapy to deliver nucleic acids with multivalent cationic vectors. Adv Colloid Interf Sci 2016;233:161-75.

[58] Xia Y, Tian J, Chen X. Effect of surface properties on liposomal siRNA delivery. Biomaterials 2016;79:56-68.

[59] Grassi G, Schneider A, Engel S, Racchi G, Kandolf R, Kuhn A. Hammerhead ribozymes targeted against cyclin E and E2F1 cooperate to down-regulate coronary smooth muscle cell proliferation. J Gene Med 2005;7:1223-34.

[60] Grassi G, Farra R, Noro E, Voinovich D, Lapasin R, Dapas B, et al. Charactherization of nucleid acid molecule/liposome complexes and rheological effects on pluronic/alginate matrices. J Drug Deliv Sci Technol 2007;17:325-31.

[61] Sun J, Wang J, Yang Z. Supramolecular assembly models of siRNA delivery systems. Chin J Chem 2015;33(1):78-89.

[62] Lee YH, Judge AD, Seo D, Kitade M, Gomez-Quiroz LE, Ishikawa T, et al. Molecular targeting of CSN5 in human hepatocellular carcinoma: a mechanism of therapeutic response. Oncogene 2011;30:4175-84.

[63] Whitehead KA, Dorkin JR, Vegas AJ, Chang PH, Veiseh O, Matthews J, et al. Degradable lipid nanoparticles with predictable in vivo siRNA delivery activity. Nat Commun 2014;5:4277.

[64] Bogorad RL, Yin H, Zeigerer A, Nonaka H, Ruda VM, Zerial M, et al. Nanoparticleformulated siRNA targeting integrins inhibits hepatocellular carcinoma progression in mice. Nat Commun 2014;5:3869.

[65] Weber S, Zimmer A, Pardeike J. Solid lipid nanoparticles (SLN) and nanostructured lipid carriers (NLC) for pulmonary application: a review of the state of the art. Eur J Pharm Biopharm 2014;86:7-22.

[66] Mukherjee S, Ray S, Thakur RS. Solid lipid nanoparticles: a modern formulation approach in drug delivery system. Indian J Pharm Sci 2009;71:349-58.

[67] Kim JH, Kim Y, Bae KH, Park TG, Lee JH, Park K. Tumor-targeted delivery of paclitaxel using low density lipoprotein-mimetic solid lipid nanoparticles. Mol Pharm 2015;12:1230-41.

[68] McMahon KM, Foit L, Angeloni NL, Giles FJ, Gordon LI, Thaxton CS. Synthetic high-density lipoprotein-like nanoparticles as cancer therapy. Cancer Treat Res 2015;166:129-50.

[69] Jin J, Bae KH, Yang H, Lee SJ, Kim H, Kim Y, et al. In vivo specific delivery of cMet siRNA to glioblastoma using cationic solid lipid nanoparticles. Bioconjug Chem 2011;22:2568-72.

[70] Ahmed TA, Aljaeid BM. Preparation characterization and potential application of chitosan, chitosan derivates, and chitosan metal nanoparticles in pharmaceutical drug delivery. Drug Des Devel Ther 2016;10:483-507.

[71] Xu C, Wang J. Delivery systems for siRNA drug development in cancer therapy. Asian J Pharm Sci 2015;10(1):1-12.

[72] Hobel S, Aigner A. Polyethylenimines for siRNA and miRNA delivery in vivo. WIREs Nanomed Nanobiotechnol 2013;5:484-501.

[73] Liu L, Zheng M, Librizzi D, Renette T, Merkel OM, Kissel T. Efficient and tumor targeted siRNA delivery by Polyethylenimine-graft-polycaprolactone-block-poly (ethylene glycol)-folate (PEI-PCL-PEG-Fol). Mol Pharm 2016;13:134-43.

[74] Lee YH, Park HI, Choi JS. Novel glycol chitosan-based polymeric gene carrier synthesized by a Michael addition reaction with low molecular weight polyethylenimine. Carbohydr Polym 2016;137:669-77.

[75] Bentley MD, Roberts MJ, Harris JM. Chemistry for peptide and protein PEGylation. Adv Drug Deliv Rev 2002;54:459-76.

[76] Salmaso S, Caliceti P. Stealth properties to improve therapeutic efficacy of drug nanocarriers. J Drug Deliv 2013;374252.

[77] Bao Y, Jin Y, Chivukula P, Zhang J, Liu Y, Liu J, et al. Effect of PEGylation on biodistribution and gene silencing of siRNA/lipid nanoparticle complexes. Pharm Res 2013;30:342-51.

[78] Muralidharan P, Mallory E, Malapit M, Hayes Jr. D, Mansour HM. Inhalable PEGylated phospholipid nanocarriers and PEGylated therapeutics for respiratory delivery as aerosolized colloidal dispersions and dry powder inhalers. Pharmaceutics 2014;6:333-53.

[79] Cavallaro G, Licciardi M, Amato G, Sardo C, Giammona G, Farra R, et al. Synthesis and characterization of polyaspartamide copolymers obtained by ATRP for nucleic acid delivery. Int J Pharm 2014;466:246-57.

[80] Sardo C, Farra R, Licciardi M, Dapas B, Scialabba C, Giammona G, et al. Development of a simple, biocompatible and cost-effective inulin-diethylenetriamine based siRNA delivery system. Eur J Pharm Sci 2015;75:60-71.

[81] Yang Y, Yuan SX, Zhao LH, Wang C, Ni JS, Wang ZG, et al. Ligand-directed stearic acid grafted chitosan micelles to increase therapeutic efficacy in hepatic cancer. Mol Pharm 2015;12:644-52.

[82] Pasut G. Polymers for protein conjugation. Polymers 2014;6:160-78.

[83] Lallana E, Tirelli N. Oxidation-responsive polymers: which groups to use, how to make them, what to expect from them (biomedical applications). Macromol Chem Phys 2013;214:143-58.

[84] Mountain A. Gene therapy: the first decade. Trends Biotechnol 2000;18(3):119-28.

[85] Du F-S, Wang Y, Zhang R, Li Z-C. Intelligent nucleic acid delivery systems based on stimuli-responsive polymers. Soft Matter 2010;6(5):835-48.

[86] Yue Y, Wu C. Progress and perspectives in developing polymeric vectors for in vitro gene delivery. Biomater Sci 2013;1(2):152-70.
[87] Park TG, Jeong JH, Kim SW. Current status of polymeric gene delivery systems. Adv Drug Deliv Rev 2006;58(4):467-86.

[88] Nguyen DN, Green JJ, Chan JM, Langer R, Anderson DG. Polymeric materials for gene delivery and DNA vaccination. Adv Mater 2009;21(8):847-67.

[89] Vaheri A, Pagano JS. Infectious poliovirus RNA: a sensitive method of assay. Virology 1965;27(3):434-6.

[90] Köping-Höggård M, Tubulekas I, Guan H, Edwards K, Nilsson M, Vårum KM, et al Chitosan as a nonviral gene delivery system. Structure-property relationships and characteristics compared with polyethylenimine in vitro and after lung administration in vivo. Gene Ther 2001;8(14):1108-21.

[91] Saranya N, Moorthi A, Saravanan S, Devi MP, Selvamurugan N. Chitosan and its derivatives for gene delivery. Int J Biol Macromol 2011;48(2):234-8.

[92] Zhang X, Oulad-Abdelghani M, Zelkin AN, Wang Y, Haîkel Y, Mainard D, et al. Poly(l-lysine) nanostructured particles for gene delivery and hormone stimulation. Biomaterials 2010;31(7):1699-706.

[93] Lungwitz U, Breunig M, Blunk T, Göpferich A. Polyethylenimine-based non-viral gene delivery systems. Eur J Pharm Biopharm 2005;60(2):247-66.

[94] Agarwal S, Zhang Y, Maji S, Greiner A. PDMAEMA based gene delivery materials. Mater Today 2012;15(9):388-93.

[95] Lynn DM, Langer R. Degradable poly( $\beta$-amino esters): synthesis, characterization and self-assembly with plasmid DNA. J Am Chem Soc 2000;122(44):10761-8.

[96] Parhamifar L, Larsen AK, Hunter AC, Andresen TL, Moghimi SM. Polycation cytotoxicity: a delicate matter for nucleic acid therapy-focus on polyethylenimine. Soft Matter 2010;6(17):4001-9.

[97] Liu Z, Zhang Z, Zhou C, Jiao Y. Hydrophobic modifications of cationic polymers for gene delivery. Prog Polym Sc 2010;35(9):1144-62.

[98] Schaffert D, Wagner E. Gene therapy progress and prospects: synthetic polymerbased systems. Gene Ther 2008;15(16):1131-8.

[99] Remaut K, Sanders NN, De Geest BG, Braeckmans K, Demeester J, De Smedt SC. Nucleic acid delivery: where material sciences and bio-sciences meet. Mater Sci Eng R-Rep 2007;58(3-5):117-61.

[100] Lin C, Engbersen JFJ. The role of the disulfide group in disulfide-based polymeric gene carriers. Expert Opin Drug Deliv 2009;6(4):421-39.

[101] Meng F, Hennink WE, Zhong Z. Reduction-sensitive polymers and bioconjugates for biomedical applications. Biomaterials 2009;30(12):2180-98.

[102] Majewski AP, Schallon A, Jérôme V, Freitag R, Müller AHE, Schmalz H. Dualresponsive magnetic core-shell nanoparticles for nonviral gene delivery and cell separation. Biomacromolecules 2012;13(3):857-66.

[103] Matyjaszewski K. Atom transfer radical polymerization (ATRP): current status and future perspectives. Macromolecules 2012;45(10):4015-39.

[104] Fournier D, Hoogenboom R, Schubert US. Clicking polymers: a straightforward approach to novel macromolecular architectures. Chem Soc Rev 2007;36(8):1369-80.

[105] Golas PL, Matyjaszewski K. Click chemistry and ATRP: a beneficial union for the preparation of functional materials. QSAR Comb Sci 2007;26(11-12):1116-34.

[106] Hoyle CE, Bowman CN. Thiol-ene click chemistry. Angew Chem Int Ed 2010;49(9):1540-73.

[107] Wang JS, Matyjaszewski K. Controlled/"living" radical polymerization. Atom transfer radical polymerization in the presence of transition-metal complexes. J Am Chem Soc 1995;117(20):5614-5.

[108] Moad G, Rizzardo E, Thang SH. Radical addition-fragmentation chemistry in polymer synthesis. Polymer 2008;49(5):1079-131.

[109] Chiefari J, Chong YKB, Ercole F, Krstina J, Jeffery J, Le TPT, et al. Living freeradical polymerization by reversible addition-fragmentation chain transfer: the RAFT process. Macromolecules 1998;31(16):5559-62.

[110] Ahmed M, Narain R. Progress of RAFT based polymers in gene delivery. Prog Polym Sci 2013:38(5):767-90.

[111] Boyer C, Corrigan NA, Jung K, Nguyen D, Nguyen TK, Adnan NN, et al. Coppermediated living radical polymerization (atom transfer radical polymerization and copper(0) mediated polymerization): from fundamentals to bioapplications. Chem Rev 2016;116(4):1803-949.

[112] Heath WH, Senyurt AF, Layman J, Long TE. Charged polymers via controlled radical polymerization and their implications for gene delivery. Macromol Chem Phys 2007;208(12):1243-9.

[113] Yin L, Song Z, Kim KH, Zheng N, Tang H, Lu H, et al. Reconfiguring the architectures of cationic helical polypeptides to control non-viral gene delivery. Biomaterials 2013;34(9):2340-9.

[114] Nakayama Y, Masuda T, Nagaishi M, Hayashi M, Ohira M, Harada-Shiba M. High performance gene delivery polymeric vector: nano-structured cationic star polymers (star vectors). Curr Drug Deliv 2005;2(1):53-7.

[115] Dai F, Sun P, Liu Y, Liu W. Redox-cleavable star cationic PDMAEMA by arm-first approach of ATRP as a nonviral vector for gene delivery. Biomaterials 2010;31(3):559-69.

[116] Schallon A, Jérôme V, Walther A, Synatschke CV, AHE, Freitag R.. Performance of three PDMAEMA-based polycation architectures as gene delivery agents in comparison to linear and branched PEI. React Funct Polym 2010;70(1):1-10.

[117] Kronberg B, Holmberg K, Lindman B. Surface chemistry of surfactants and polymers. Chichester: John Wiley \& Sons Ltd; 2014. p. 1-479.

[118] Bombelli C, Giansanti L, Luciani P, Mancini G. Gemini surfactant based carriers in gene and drug delivery. Curr Med Chem 2009;16(2):171-83.

[119] Papahadjopoulos D, N.Y.A.o. Sciences. Liposomes and their uses in biology and medicine. New York Academy of Sciences; 1978.

[120] Knight CG. Liposomes, from physical structure to therapeutic applications. Elsevier/North-Holland Biomedical Press; 1981.

[121] Ostro MJ. Liposomes: From Biophysics to Therapeutics. New York: Marcel Dekker; 1987.

[122] Gregoriadis G. Liposomes as Drug Carriers: Recent Trends and Progress. New York: John Wiley \& Sons; 1988. 
[123] Templeton NS. Cationic liposomes as in vivo delivery vehicles. Curr Med Chem 2003;10:1279-87.

[124] Pedroso de Lima MC, Neves S, Filipe A, Düzgüneș N, Simões S. Cationic liposomes for gene delivery: from biophysics to biological applications. Curr Med Chem 2003;10:1221-31.

[125] Zhao Y, Huang L. Lipid nanoparticles for gene delivery. Adv Genet 2014;88:13-36.

[126] Dias R, Lindman B. DNA interactions with polymers and surfactants. Wiley; 2008.

[127] Damen J, Regts J, Scherphof G. Transfer and exchange of phospholipid between small unilamellar liposomes and rat plasma high density lipoproteins. Dependence on cholesterol content and phospholipid composition. Biochim Biophys Acta 1981;665(3):538-45.

[128] Semple SC, Chonn A, Cullis PR. Influence of cholesterol on the association of plasma proteins with liposomes. Biochemistry 1996;35(8):2521-5.

[129] Jokerst JV, Lobovkina T, Zare RN, Gambhir SS. Nanoparticle PEGylation for imaging and therapy. Nanomedicine 2011;6(4):715-28.

[130] Dias R, Antunes F, Miguel M, Lindman S, Lindman B. DNA-lipid systems. A physical chemistry study. Braz J Med Biol Res 2002;35(5):509-22.

[131] Malone RW, Felgner PL, Verma IM. Cationic liposome-mediated RNA transfection. Proc Natl Acad Sci U S A 1989;86(16):6077-81.

[132] Hafez IM, Maurer N, Cullis PR. On the mechanism whereby cationic lipids promote intracellular delivery of polynucleic acids. Gene Ther 2001;8(15):1188-96.

[133] Iannitti T, Palmieri B. Therapeutical use of probiotic formulations in clinical practice. Clin Nutr 2010;29(6):701-25.

[134] Passariello A, Agricole P, Malfertheiner P. A critical appraisal of probiotics (as drugs or food supplements) in gastrointestinal diseases. Curr Med Res Opin 2014;30(6):1055-64.

[135] Holzapfel WH, Haberer P, Snel J, Schillinger U. Huis in't Veld JH. Overview of gut flora and probiotics. Int J Food Microbiol 1998;41(2):85-101.

[136] Tremaroli V, Backhed F. Functional interactions between the gut microbiota and host metabolism. Nature 2012;489(7415):242-9.

[137] Woting A, Blaut M. The intestinal microbiota in metabolic disease. Forum Nutr 2016;8(4):202

[138] De Vadder F, Kovatcheva-Datchary P, Goncalves D, Vinera J, Zitoun C, Duchampt A, et al. Microbiota-generated metabolites promote metabolic benefits via gutbrain neural circuits. Cell 2014;156(1-2):84-96.

[139] Cani PD, Possemiers S, Van de Wiele T, Guiot Y, Everard A, Rottier O, et al. Changes in gut microbiota control inflammation in obese mice through a mechanism involving GLP-2-driven improvement of gut permeability. Gut 2009:58(8):1091-103.

[140] Larsson E, Tremaroli V, Lee YS, Koren O, Nookaew I, Fricker A, et al. Analysis of gut microbial regulation of host gene expression along the length of the gut and regulation of gut microbial ecology through MyD88. Gut 2012;61(8):1124-31.

[141] Maynard CL, Elson CO, Hatton RD, Weaver CT. Reciprocal interactions of the intestinal microbiota and immune system. Nature 2012;489(7415):231-41.

[142] Cook MT, Tzortzis G, Charalampopoulos D, Khutoryanskiy VV. Microencapsulation of probiotics for gastrointestinal delivery. J Control Release 2012;162(1):56-67.

[143] Haffner FB, Diab R, Pasc A. Encapsulation of probiotics: insights into academic and industrial approaches. AIMS Materials Science 2016;3(1):114-36.

[144] Corona-Hernandez RI, Álvarez-Parrilla E, Lizardi-Mendoza J, Islas-Rubio AR, de la Rosa LA, Wall-Medrano A. Structural stability and viability of microencapsulated probiotic bacteria: a review. Compr Rev Food Sci Food Saf 2013;12(6):614-28.

[145] Priya James H, John R, Alex A, Anoop KR. Smart polymers for the controlled delivery of drugs - a concise overview. Acta Pharm Sin B 2014;4(2):120-7.

[146] El-Sherbiny IM. Enhanced pH-responsive carrier system based on alginate and chemically modified carboxymethyl chitosan for oral delivery of protein drugs: preparation and in-vitro assessment. Carbohydr Polym 2010;80(4):1125-36.

[147] Chang CY, Zhang LN. Cellulose-based hydrogels: present status and application prospects. Carbohydr Polym 2011;84(1):40-53.

[148] Sato M, Yokoyama U, Fujita T, Okumura S, Ishikawa Y. The roles of cytochrome p450 in ischemic heart disease. Curr Drug Metab 2011;12(6):526-32.

[149] Falkenberg KJ, Johnstone RW. Histone deacetylases and their inhibitors in cancer, neurological diseases and immune disorders. Nat Rev Drug Discov 2014;13(9):673-91.

[150] Bartelmess J, Giordani S. Carbon nano-onions (multi-layer fullerenes): chemistry and applications. Beilstein J Nanotechnol 2014;5:1980-8.

[151] Miyako E, Russier J, Mauro M, Cebrian C, Yawo H, Ménard-Moyon C, et al Photofunctional nanomodulators for bioexcitation. Angew Chem Int Ed Eng 2014;53(48):13121-5.

[152] Finnie KS, Waller DJ, Perret FL, Krause-Heuer AM, Lin HQ, Hanna JV, et al. Biodegradability of sol-gel silica microparticles for drug delivery. J Sol-Gel Sci Techn 2009;49:12-8.

[153] Swietach P, Patiar S, Supuran CT, Harris AL, Vaughan-Jones RD. Biodegradability of sol-gel silica microparticles for drug delivery. J Biol Chem 2009;284(30):20299-310.

[154] Schumacker PT. Reactive oxygen species in cancer cells: live by the sword, die by the sword. Cancer Cell 2006;10(3):175-6.

[155] Wang L, Zhou H, Wang Y, Cui G, Di LJ. CtBP maintains cancer cell growth and metabolic homeostasis via regulating SIRT4. Cell Death Dis 2015;6:e1620.

[156] Masuda K, An HS. Growth factors and the intervertebral disc. Spine J 2004;4(6 Suppl):330S-40S.

[157] Ahearne M. Introduction to cell-hydrogel mechanosensing. Interface Focus 2014;4:20130038.

[158] Lee KY, Mooney DJ. Hydrogels for tissue engineering. Chem Rev 2001;101(7):1869-80.

[159] Fernández-Colino A, Arias FJ, Alonso M, Rodríguez-Cabello JC. Self-organized ECM-mimetic model based on an amphiphilic multiblock silk-elastin-like corecombinamer with a concomitant dual physical gelation process.
Biomacromolecules 2014;15:3781-93.

[160] Peppas NA, Hilt JZ, Khademhosseini A, Langer R. Hydrogels in biology and medicine: from molecular principles to bionanotechnology. Adv Mater 2006;18:1345e60.

[161] O'Leary LER, Fallas JA, Bakota EL, Kang MK, Hartgerink JD. Multi-hierarchica self-assembly of a collagen mimetic peptide from triple helix to nanofibre and hydrogel. Nat Chem 2011:3:821-8.

[162] Villard V, Kalyuzhniy O, Riccio O, Potekhin S, Melnik TN, Kajava AV, et al. Synthetic RGD-containing alpha-helical coiled coil peptides promote integrin-dependent cell adhesion. J Pept Sci 2006;12:206-12.

[163] Luo Z, Zhao X, Zhang S. Structural dynamic of a self-assembling peptide d-EAK16 made of only D-amino acids. PLoS One 2008;3:e2364.

[164] Altunbas A, Lee SJ, Rajasekaran SA, Schneider JP, Pochan DJ. Encapsulation of curcumin in self-assembling peptide hydrogels as injectable drug delivery vehicles. Biomaterials 2011;32:5906-14.

[165] Briuglia M-L, Urquhart AJ, Lamprou DA. Sustained and controlled release of lipophilic drugs from a self-assembling amphiphilic peptide hydrogel. Int J Pharm 2014;474:103-11.

[166] Bakota EL, Wang Y, Danesh FR, Hartgerink JD. Injectable multidomain peptide nanofiber hydrogel as a delivery agent for stem cell secretome. Biomacromolecules 2011;12:1651-7.

[167] Galler KM, Aulisa L, Regan KR, D'Souza RN, Hartgerink JD. Self-assembling multidomain peptide hydrogels: designed susceptibility to enzymatic cleavage allows enhanced cell migration and spreading. J Am Chem Soc 2010;132:3217-23.

[168] Thomas D, Fontana G, Chen X, Sanz-Nogués C, Zeugolis DI, Dockery P, et al. A shape-controlled tuneable microgel platform to modulate angiogenic paracrine responses in stem cells. Biomaterials 2014;35:8757-66.

[169] Fontana G, Thomas D, Collin E, Pandit A. Microgel microenvironment primes adipose-derived stem cells towards an NP cells-like phenotype. Adv Healthc Mater 2014;3:2012-22.

[170] Kopesky PW, Vanderploeg EJ, Sandy JS, Kurz B, Grodzinsky AJ. Self-assembling peptide hydrogels modulate in vitro chondrogenesis of bovine bone marrow stromal cells. Tissue Eng Part A 2010;16:465-77.

[171] Santo VE, Gomes ME, Mano JF, Reis RL. Controlled release strategies for bone, cartilage, and osteochondral engineering-part II: challenges on the evolution from single to multiple bioactive factor delivery. Tissue Eng Part B Rev 2013;19:327-52.

[172] Webber MJ, Newcomb CJ, Bitton R, Stupp SI. Switching of self-assembly in a peptide nanostructure with a specific enzyme. Soft Matter 2011;7:9665-72.

[173] Tian YF, Hudalla GA, Han H, Collier JH. Controllably degradable $\beta$-sheet nanofibers and gels from self-assembling depsipeptides. Biomater Sci 2013;1:1037-45.

[174] Hoffman AS. Hydrogels for biomedical applications. Adv Drug Deliv Rev 2002;54:3e12.

[175] Du Y, Lo E, Ali S, Khademhosseini A. Directed assembly of cell-laden microgels for fabrication of 3D tissue constructs. Proc Natl Acad Sci U S A 2008;105:9522e7.

[176] Ifkovits JL, Burdick JA. Review: photopolymerizable and degradable biomaterials for tissue engineering applications. Tissue Eng 2007;13:2369e85.

[177] Whitesides GM, Grzybowski B. Self-assembly at all scales. Science $2002 ; 295: 2418-21$.

[178] Andreozzi P, Funari SS, La Mesa C, Mariani P, Ortore MG, Sinibaldi R, et al. Multito unilamellar transitions in catanionic vesicles. J Phys Chem B 2010;114:8056-60.

[179] Bonincontro A, Falivene M, La Mesa C, Risuleo G, Ruiz-Pena M. Dynamics of DNA adsorption on and release from SDS-DDAB cat-anionic vesicles: a multitechnique study. Langmuir 2008;24:1973-8.

[180] Guida V. Thermodynamics and kinetics of vesicles formation processes. Adv Colloid Interf Sci 2010;16:77-88.

[181] Kaler EW, Murthy AK, Rodriguez BE, Zasadzinski JA. Spontaneous vesicle formation in aqueous mixtures of single-tailed surfactants. Science 1989;245:1371-4.

[182] Antunes FE, Marques EF, Miguel MG, Lindman B. Polymer-vesicle association. Adv Colloid Interf Sci 2009;147-148:18-35.

[183] Liechty WB, Kryscio DR, Slaughter BV, Peppas NA. Polymers for drug delivery systems. Annu Rev Chem Biomol 2010;1:149-73.

[184] Poole KM, Nelson CE, Joshi RV, Martin JR, Gupta MK, Haws SC, et al. ROS-responsive microspheres for on demand antioxidant therapy in a model of diabetic peripheral arterial disease. Biomaterials 2015;41:166-75.

[185] Browne S, Fontana G, Rodriguez BJ, Pandit A. A protective extracellular matrixbased gene delivery reservoir fabricated by electrostatic charge manipulation. Mo Pharm 2012;9:3099-106.

[186] Kraskiewicz H, Breen B, Sargeant T, McMahon S, Pandit A. Assembly of proteinbased hollow spheres encapsulating a therapeutic factor. ACS Chem Neurosci 2013;4:1297-304.

[187] Craik DJ, Fairlie DP, Liras S, Price D. The future of peptide-based drugs. Chem Biol Drug Des 2013;81(1):136-47.

[188] Newman DJ, Cragg GM. Natural products as sources of new drugs over the 30 years from 1981 to 2010. J Nat Prod 2012;75(3):311-35.

[189] Koide H, Asai T, Hatanaka K, Urakami T, Ishii T, Kenjo E, et al. Particle sizedependent triggering of accelerated blood clearance phenomenon. Int J Pharm 2008;362(1-2):197-200.

[190] Hörter D, Dressman J. Influence of physicochemical properties on dissolution of drugs in the gastrointestinal tract. Adv Drug Deliv Rev 2001;46:75-87.

[191] Yin Win K, Feng S-S. Effects of particle size and surface coating on cellular uptake of polymeric nanoparticles for oral delivery of anticancer drugs. Biomaterials 2005;26:2713-22.

[192] De Sousa IP, Bernkop-Schnürch A. Pre-systemic metabolism of orally administered drugs and strategies to overcome it. J Control Release 2014;192:301-9.

[193] Zhang Y, Benet LZ. The gut as a barrier to drug absorption. Clin Pharmacokinet 
2001;40(3):159-68.

[194] Hume DA. The mononuclear phagocyte system. Curr Opin Immunol 2006;18(1):49-53.

[195] Dahan A, Miller JM, Amidon GL. Prediction of solubility and permeability class membership: provisional BCS classification of the world's top oral drugs. AAPS 2009;11:740-6.

[196] Leuner C, Dressman J. Improving drug solubility for oral delivery using solid dispersions. Eur J Pharm Biopharm 2000;50:47-60.

[197] Rasenack N, Müller BW. Micron-size drug particles: common and novel micronization techniques. Pharm Dev Technol 2004;9:1-13.

[198] Jinno J, Kamada N, Miyake M, Yamada K, Mukai T, Odomi M, et al. Effect of particle size reduction on dissolution and oral absorption of a poorly water-soluble drug, cilostazol, in beagle dogs. J Control Release 2006;111:56-64.

[199] Shibata Y, Fujii M, Suzuki A, Koizumi N, Kanada K, Yamada M, et al. Effect of storage conditions on the recrystallization of drugs in solid dispersions with crospovidone. Pharm Dev Technol 2014;19(4):468-74.

[200] Yoshioka S, Stella VJ. Stability of drugs and dosage forms. Springer; 2000.

[201] Eibl H, Kaufmann-Kolle P. Medical application of synthetic phospholipids as liposomes and drugs. J Liposome Res 1995;5(1):131-48.

[202] Agashe H, Lagisetty P, Awasthi S, Awasthi V. Improved formulation of liposomeencapsulated hemoglobin with an anionic non-phospholipid. Colloids Surf B: Biointerfaces 2010;75:573-83.

[203] Castile JD, Taylor KM. Factors affecting the size distribution of liposomes produced by freeze-thaw extrusion. Int J Pharm 1999;188(1):87-95.

[204] Villasmil-Sánchez S, Rabasco AM, González-Rodríguez ML. Thermal and 31P-NMR studies to elucidate sumatriptan succinate entrapment behavior in phosphatidylcholine/cholesterol liposomes. Comparative 31P-NMR analysis on negatively and positively-charged liposomes. Colloids Surf B: Biointerfaces 2013;105:14-23.

[205] Guinedi AS, Mortada ND, Mansour S, Hathout RM. Preparation and evaluation of reverse-phase evaporation and multilamellar niosomes as ophthalmic carriers of acetazolamide. Int J Pharm 2005 2005;306(1-2):71-82.

[206] Maestrelli F, González-Rodríguez ML, Rabasco AM, Mura P. Effect of preparation technique on the properties of liposomes encapsulating ketoprofen-cyclodextrin complexes aimed for transdermal delivery. Int J Pharm 2006;312(1):53-60.

[207] Muppidi K, Pumerantz AS, Wang J, Betageri G. Development and stability studies of novel liposomal vancomycin formulations. ISRN Pharm 2012;2012:1-8.

[208] Mallick S, Choi JS. Liposomes: versatile and biocompatible nanovesicles for efficient biomolecules delivery. J Nanosci Nanotechnol 2014;14:755-65.

[209] Patil YP, Jadhav S. Novel methods for liposome preparation. Chem Phys Lipids 2014;177:8-18.

[210] Grimaldi N, Andrade F, Segovia N, Ferrer-Tasies L, Sala S, Veciana J, et al. Lipidbased nanovesicles for nanomedicine. Chem Soc Rev 2016;45(23):6520-45.

[211] Jahn A, Vreeland WN, DeVoe DL, Locascio LE, Gaitan M. Microfluidic directed formation of liposomes of controlled size. Langmuir 2007;23:6289-93.

[212] Davies RT, Kim D, Park J. Formation of liposomes using a 3D flow focusing microfluidic device with spatially patterned wettability by corona discharge. J Micromech Microeng 2012;22(5):055003.

[213] Guan P, Lu Y, Qi J, Niu M, Lian R, Hu F, et al. Enhanced oral bioavailability of cyclosporine A by liposomes containing a bile salt. Int $\mathrm{J}$ Nanomedicine 2011;6(965):e974.

[214] Cabrera I, Elizondo E, Esteban O, Corchero JL, Melgarejo M, Pulido D, et al. Multifunctional nanovesicle-bioactive conjugates prepared by a one-step scalable method using CO2-expanded solvents. Nano Lett 2013:13(8):3766-74.

[215] Yokoyama M. Clinical applications of polymeric micelle carrier systems inchemotherapy and image diagnosis of solid tumors. J Exp Clin Med 2011;3:151-8.

[216] Moen MD, Lyseng-Williamson KA, Scott LJ. Liposomal amphotericin B:a review of its use as empirical therapy in febrile neutropenia and in thetreatment of invasive fungal infections. Drugs 2009;69:361-92.

[217] Scott RC, Wang B, Nallamothu R, Pattillo CB, Perez-Liz G, Issekutz A, et al. Targeted delivery of antibody conjugated liposomal drug carriers to rat myocardial infarction. Biotechnol Bioeng 2007;96(4):795-802.

[218] Tseng YL, Liu JJ, Hong RL. Translocation of liposomes into cancer cells by cellpenetrating peptides penetratin and tat: a kinetic and efficacy study. Mol Pharmacol 2002;62(4):864-72.

[219] Perche F, Torchilon VP. Recent trends in multifunctional liposomal nanocar-riers for enhanced tumor targeting. J Drug Deliv 2013;2013:1-32.

[220] Heurtault B, Saulnier P, Pech B, Proust JE, Benoit JP. Physico-chemical stability of colloidal lipid particles. Biomaterials 2003;24(23):4283-300.

[221] El-Nesr OH, Yahiya SA, El-Gazayerly ON. Effect of formulation design and freezedrying on properties of fluconazole multilamellar liposomes. Saudi Pharm J 2010;18:217-24.

[222] Kumar GP, Rajeshwarrao P. Nonionic surfactant vesicular systems for effective drug delivery - an overview. Acta Pharm Sin B 2011;1:208-19.

[223] Marianecci C, Paolino D, Celia C, Fresta M, Carafa M, Alhaique F. Non-ionic surfactant vesicles in pulmonary glucocorticoid delivery: characterization and interaction with human lung fibroblasts. J Control Release 2010;147:127-35.

[224] Karn PR, Vanić Z, Pepić I, Škalko-Basnet N. Mucoadhesive liposomal delivery systems: the choice of coating material. Drug Dev Ind Pharm 2011;37(4):482-8.

[225] Sigg SJ, Schuster TB, Meier WP. Self-assembled structures from amphiphilic peptides. Chimia 2013;67(12):881-4.

[226] Manosroi A, Wongtrakul P, Manosroi J, Sakai H, Sugawara F, Yuasa M, et al. Characterization of vesicles prepared with various non-ionic surfactants mixed with cholesterol. Colloids Surf B: Biointerfaces 2003;30:129-38.

[227] Rajera R, Nagpal K, Singh SK, Mishra DN. Niosomes: a controlled and novel drug delivery system. Biol Pharm Bull 2011;34(7):945-53.

[228] Zhigaltsev IV, Maurer N, Akhong QF, Leone R, Leng E, Wang J, et al. Liposome- encapsulated vincristine, vinblastine and vinorelbine: a comparative study of drug loading and retention. J Control Release 2005;104:103-11.

[229] Semalty A, Semalty M, Rawat BS, Singh D, Rawat MSM. Pharmacosomes: the lipidbased new drug delivery system. Expert Opin Drug Delivery 2009;6:599-612.

[230] Cano-Sarabia M, Angelova A, Ventosa N, Lesieur S, Veciana J. Cholesterol induced CTAB micelle-to-vesicle phase transitions. J Colloid Interface Sci 2010;350:10-5.

[231] Elizondo E, Larsen J, Hatzakis NS, Cabrera I, Bjørnholm T, Veciana J, et al. Influence of the preparation route on the supramolecular organization of lipids in a vesicular system. J Am Chem Soc 2012;134(4):1918-21.

[232] Huang X, Caddell R, Yu B, Xu S, Theobald B, Lee LJ, et al. Ultrasound-enhanced microfluidic synthesis of liposomes. Anticancer Res 2010;30(2):463-6.

[233] Manconi M, Sinico C, Valenti D, Loy G, Fadda AM. Niosomes as carriers for tretinoin. I. Preparation and properties. Int J Pharm 2002;234(1):237-48.

[234] Chen Y, Lu Y, Chen J, Lai J, Sun J, Hu F, et al. Enhanced bioavailability of the poorly water-soluble drug fenofibrate by using liposomes containing a bile salt. Int J Pharm 2009;376(1):153-60.

[235] Meure LA, Foster NR, Dehghani F. Conventional and dense gas techniques for the production of liposomes: a review. AAPS Pharm Sci Tech 2008;9:798-809.

[236] Wang T, Wang N, Wang T, Sun W, Li T. Preparation of submicron liposomes exhibiting efficient entrapment of drugs by freeze-drying water-in-oil emulsions. Chem Phys Lipids 2011;164:151-7.

[237] Meure LA. The Development of a novel process for the Formation of Liposomes: Depressurisation of an Expanded Solution Into Aqueous Media (DESAM) University of New South Wales; 2004.

[238] Giordani S, Bartelmess J, Frasconi M, Biondi I, Cheung S, Grossi M, et al. NIR fluorescence labelled carbon nano-onions: synthesis, analysis and cellular imaging. J Mater Chem B 2014;2(42):7459-63.

[239] Bartelmess J, Baldrighi M, Nardone V, Parisini E, Buck D, Echegoyen L, et al. Synthesis and characterization of far-red/NIR-fluorescent BODIPY dyes, solid-state fluorescence and application as fluorescent tags attached to carbon nano-onions. Chem - A Eur J 2015;21:9727-32.

[240] Bachilo SM, Strano MS, Kittrell C, Hauge RH, Smalley RE, Weisman RB. Structureassigned optical spectra of single-walled carbon nanotubes. Science 2002;298(5602):2361-6.

[241] Sun YP, Zhou B, Lin Y, Wang W, Fernando KA, Pathak P, et al. Quantum-sized carbon dots for bright and colorful photoluminescence. J Am Chem Soc 2006;128(24):7756-7.

[242] Bartelmess J, Quinn SJ, Giordani S. Carbon nanomaterials: multi-functional agents for biomedical fluorescence and Raman imaging. Chem Soc Rev 2014:44:4672_98.

[243] Wang Y, Jun Z, Fung S, Ran R, He H, Ken K, et al. Nano-urchins for rechargeable lithium-ion batteries. Carbon 2013;64:230-6.

[244] Ganesh P, Kent PRC, Mochalin V. Formation, characterization and dynamics of onion-like carbon structures for electrical energy storage from nanodiamonds using reactive force fields. J Appl Phys 2011;110:073506.

[245] Zhang J, Su D, Zhang A, Wang D, Schlögl R, Høbert C. Nanocarbon as robust catalyst: mechanistic insight into carbon-mediated catalysis. Angew Chem Int Ed 2007;46:7319-23.

[246] Pech D, Brunet M, Durou H, Huang P, Mochalin V, Gogotsi Y, et al. Ultrahighpower micrometre-sized supercapacitors based on onion-like carbon. Nat Nanotechnol 2010;5:651-4.

[247] Frasconi M, Maffeis V, Bartelmess J, Echegoyen L, Giordani S. Highly surface functionalized carbon nano-onions for bright light bioimaging. Methods Appl Fluoresc 2015;3(4):044005.

[248] Yang M, Flavin K, Kopf I, Radics G, Hearnden CHA, McManus GJ, et al. Functionalization of carbon nanoparticles modulates inflammatory cell recruitment and NLRP3 inflammasome activation. Small 2013;9(24):4194-206.

[249] Bartelmess J, De Luca E, Signorelli A, Baldrighi M, Becce M, Brescia R, et al. Boron dipyrromethene (BODIPY) functionalized carbon nano-onions for high resolution cellular imaging. Nanoscale 2014;6(22):13761-9.

[250] Frasconi M, Marotta R, Markey L, Flavin K, Spampinato V, Ceccone G, et al. Multifunctionalized carbon nano-onions as imaging probes for cancer cells. Chem Eur J 2015;21(52):19071-80.

[251] d'Amora M, Rodio M, Bartelmess J, Brescia Sancataldo G, R, Zanacchi FC, Diaspro A, Giordani S.. Biocompatibility and biodistribution of functionalized carbon nano-onions ( f-CNOs ) in a vertebrate model. Sci Rep 2016;6:33923.

[252] Jeong J, Jung J, Choi M, Kim JW, Chung SJ, Lim S, et al. Color-tunable photoluminescent fullerene nanoparticles. Adv Mater 2012;24(15):1999-2003.

[253] Tan L, Wu T, Tang Z, Xiao J, Zhuo R. Water-soluble photoluminescent fullerene capped mesoporous silica for $\mathrm{pH}$ - responsive drug delivery and bioimaging. Nanotechnology 2016;27(31):315104.

[254] Hong G, Diao S, Chang J, Antaris AL, Chen C, Zhang B, et al. Through-skull fluorescence imaging of the brain in a new near-infrared window. Nat Photonics 2014;8(9):723-30.

[255] Liu Z, Sun X, Nakayama-ratchford N, Dai H. Supramolecular chemistry on watersoluble carbon nanotubes for drug loading and delivery. ACS Nano 2007;1(1):50-6.

[256] Liu Z, Fan AC, Rakhra K, Sherlock S, Goodwin A, Chen X, et al. Supramolecular stacking of doxorubicin on carbon nanotubes for in vivo cancer therapy. Angew Chem Int Ed 2009;48:7668-72.

[257] Erbas S, Gorgulu A, Kocakusakogullaric M, Akkaya EU. Non-covalent functionalized SWCNTs as delivery agents for novel Bodipy-based potential PDT sensitizers. Chem Commun 2009;33:4956-8.

[258] Bartelmess J, Frasconi M, Balakrishnan PB, Signorelli A, Echegoyen L, Pellegrino T, et al. Non-covalent functionalization of carbon nano-onions with pyreneBODIPY dyads for biological imaging. RSC Adv 2015;5(62):50253-8.

[259] Kang Y, Li Y, Fang Y, Xu Y, Wei X, Yin X. Carbon quantum dots for zebrafish 
fluorescence imaging. Sci Report 2015;5:11835.

[260] Das SK, Luk CM, Martin WE, Tang L, Kim DY, Ping S, et al. Size and dopant dependent single particle fluorescence properties of graphene quantum dots. J Phys Chem C 2015;119(31):17988-94.

[261] Tang L, Ji R, Cao X, Lin J, Jiang H, Li X, et al. Deep ultraviolet photoluminescence of water-soluble self-passivated graphene quantum dots. ACS Nano 2012;6(6):5102-10.

[262] Bolskar RD, Benedetto AF, Husebo LO, Price RE, Jackson EF, Wallace S, et al. First soluble $\mathrm{M} @ \mathrm{C}_{60}$ derivatives provide enhanced access to metallofullerenes and permit in vivo evaluation of $\mathrm{Gd} @ \mathrm{C}_{60}\left[\mathrm{C}(\mathrm{COOH})_{2}\right]_{10}$ as a MRI contrast agent. J Am
Chem Soc 2003;125(18):5471-8.

[263] Servant A, Jacobs I, Bussy C, Fabbro C, Pach E, Ballesteros B, et al. Gadoliniumfunctionalised multi-walled carbon nanotubes as a T 1 contrast agent for MRI cell labelling and tracking. Carbon 2016;97:126-33.

[264] Dellinger A, Olson J, Link K, Vance S, Sandros MG, Yang J, et al. Functionalization of gadolinium metallofullerenes for detecting atherosclerotic plaque lesions by cardiovascular magnetic resonance. J Cardiovasc Magn Reson 2013;15(1):7.

[265] Jennings LE, Long NJ. 'Two is better than one'-probes for dual-modality molecular imaging. Chem Commun 2009;24:3511-24. 